SUS-RURI: Proceedings of a Workshop on Developing a Convergence Sustainable Urban Systems Agenda for Redesigning the Urban-Rural Interface along the Mississippi River Watershed held in Ames, lowa, August 12-13, 2019

\title{
Handmade Paper and the Landscape
}

Lee Running

Published on: Jan 13, 2020

DOI: $10.31274 / 3 d 9 e a 6 a 4.711 c 5726$

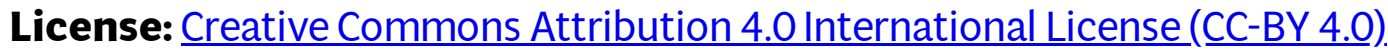


My work evolves looking at repeating patterns in the natural world. Images taken from airplanes...

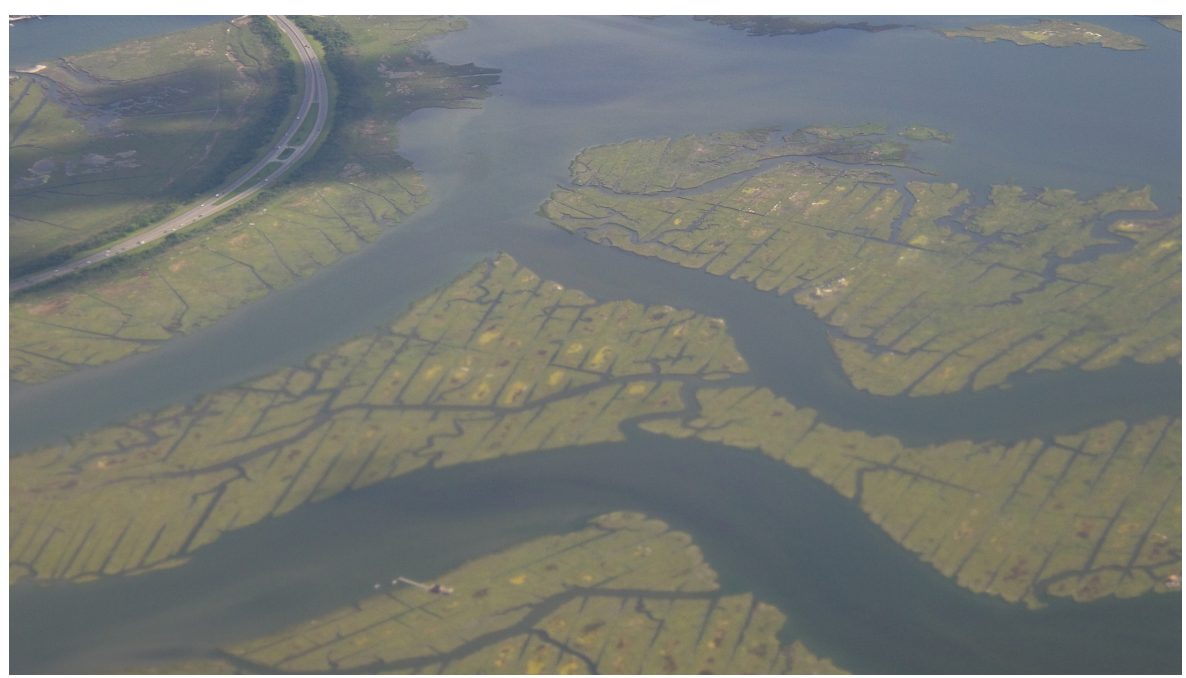

are often strikingly similar to images found in flower petals...

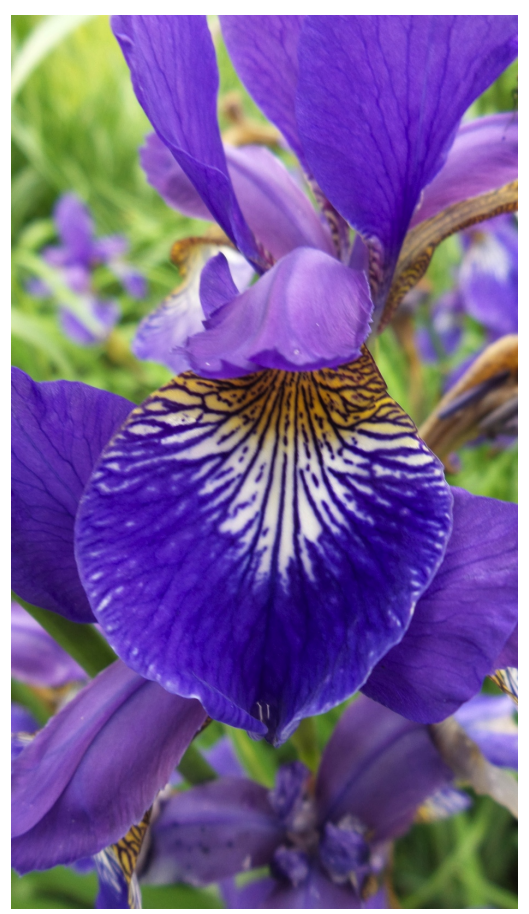

in the skins of jellyfish... 


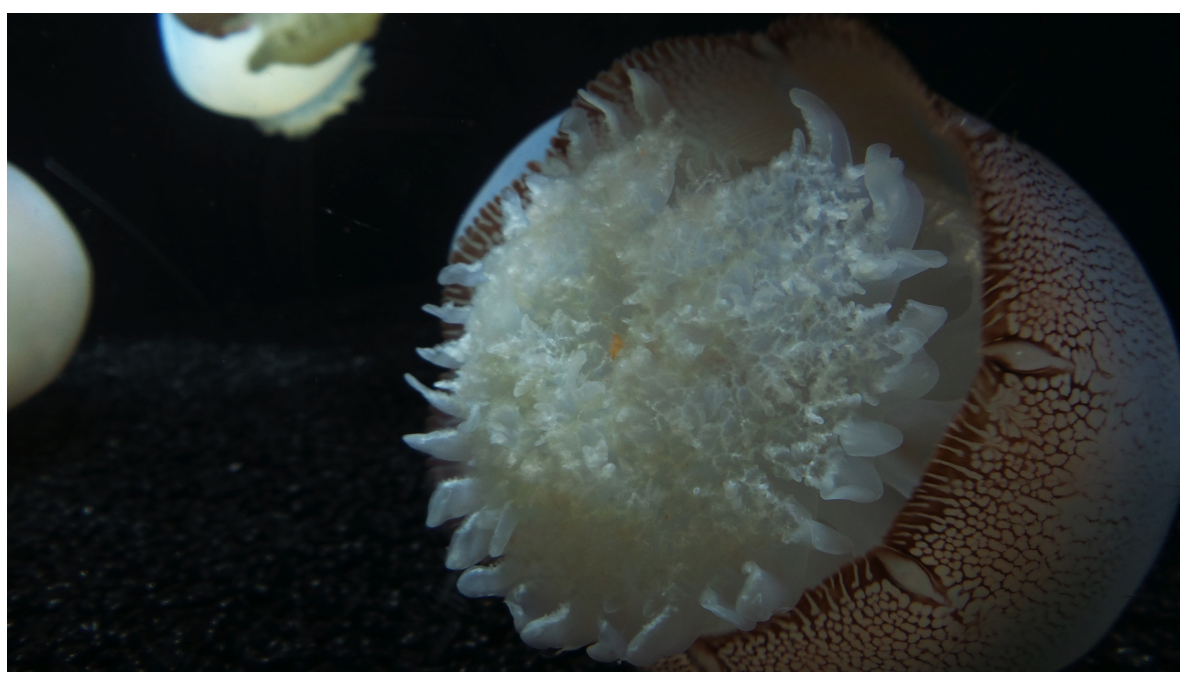

or in the layers of sedimentary rocks...

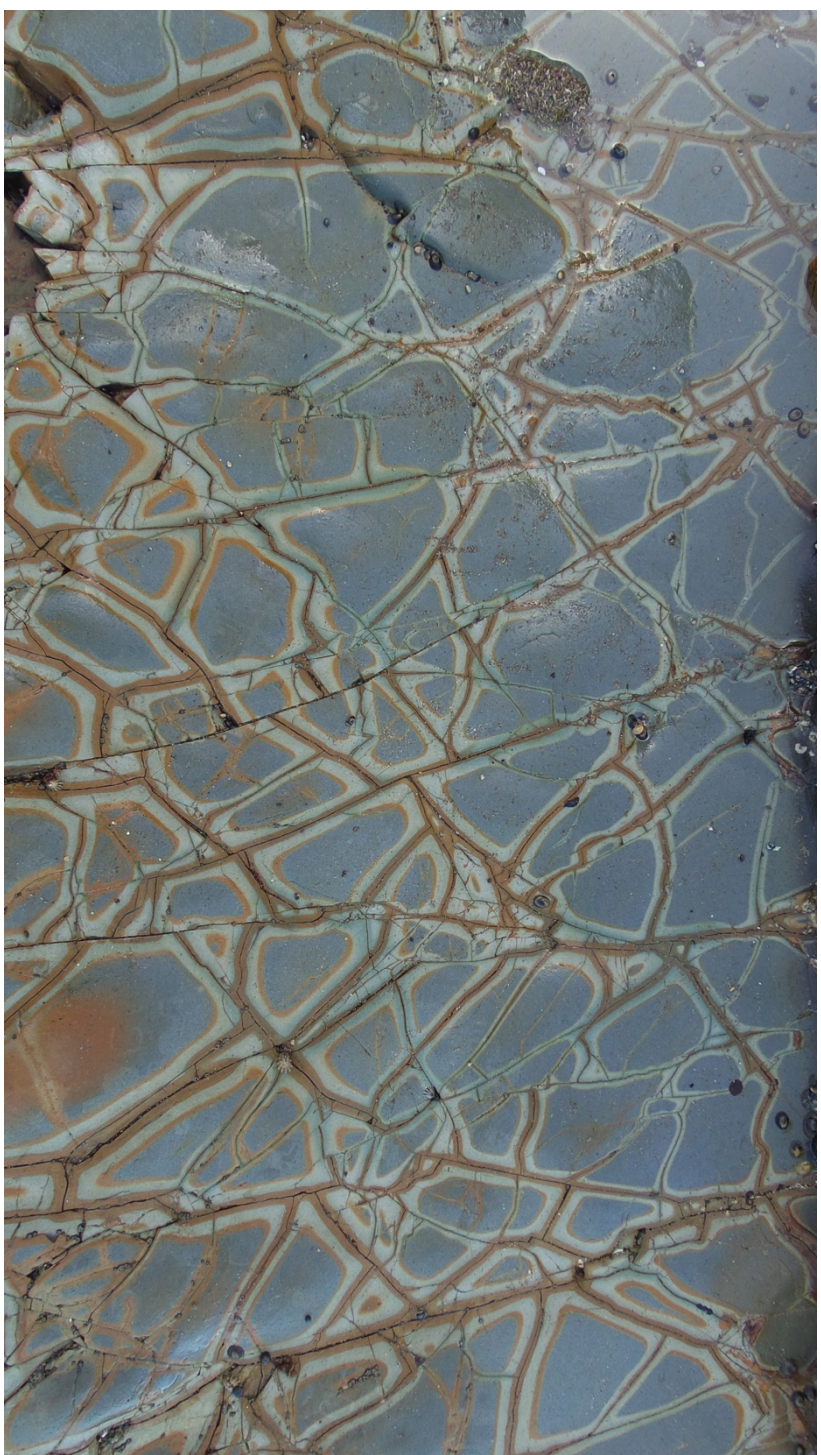


I use patterns like this in the development of large scale installations, like this piece, “Pare, " a 14' x 27' wallpaper installation at Muhlenberg College:

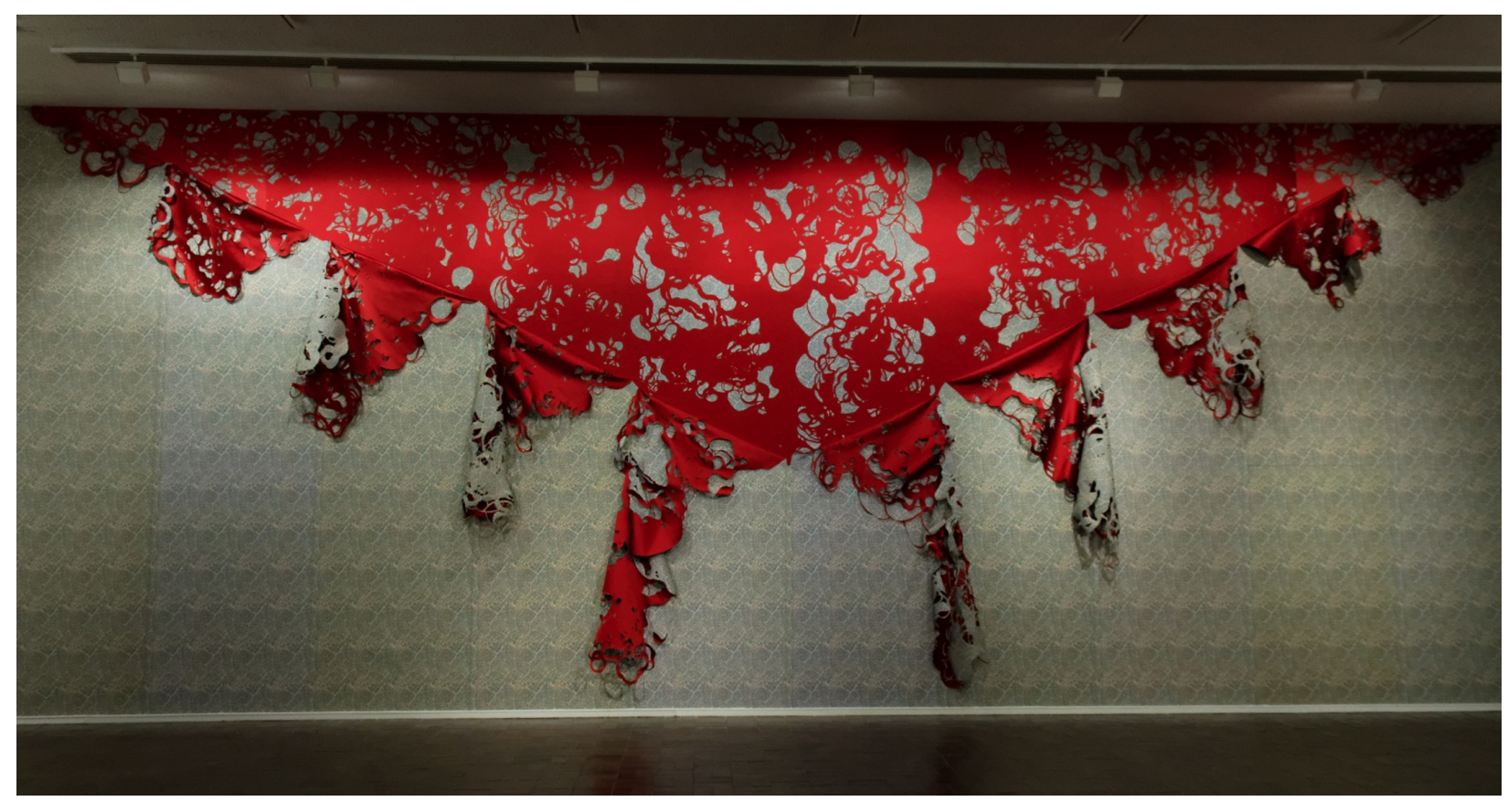

Pare, 2015

Digital print on adhesive vinyl red satin, $14 \times 41$ feet

Paper Architecture, Martin Art Gallery, Muhlenberg College, Allentown, PA

This is a detail of the wallpaper I produced from a drawing of leaf veins...

And a detail of the hand-cut paper backed with satin. The lacy network is from animal hair placed on a projector: 


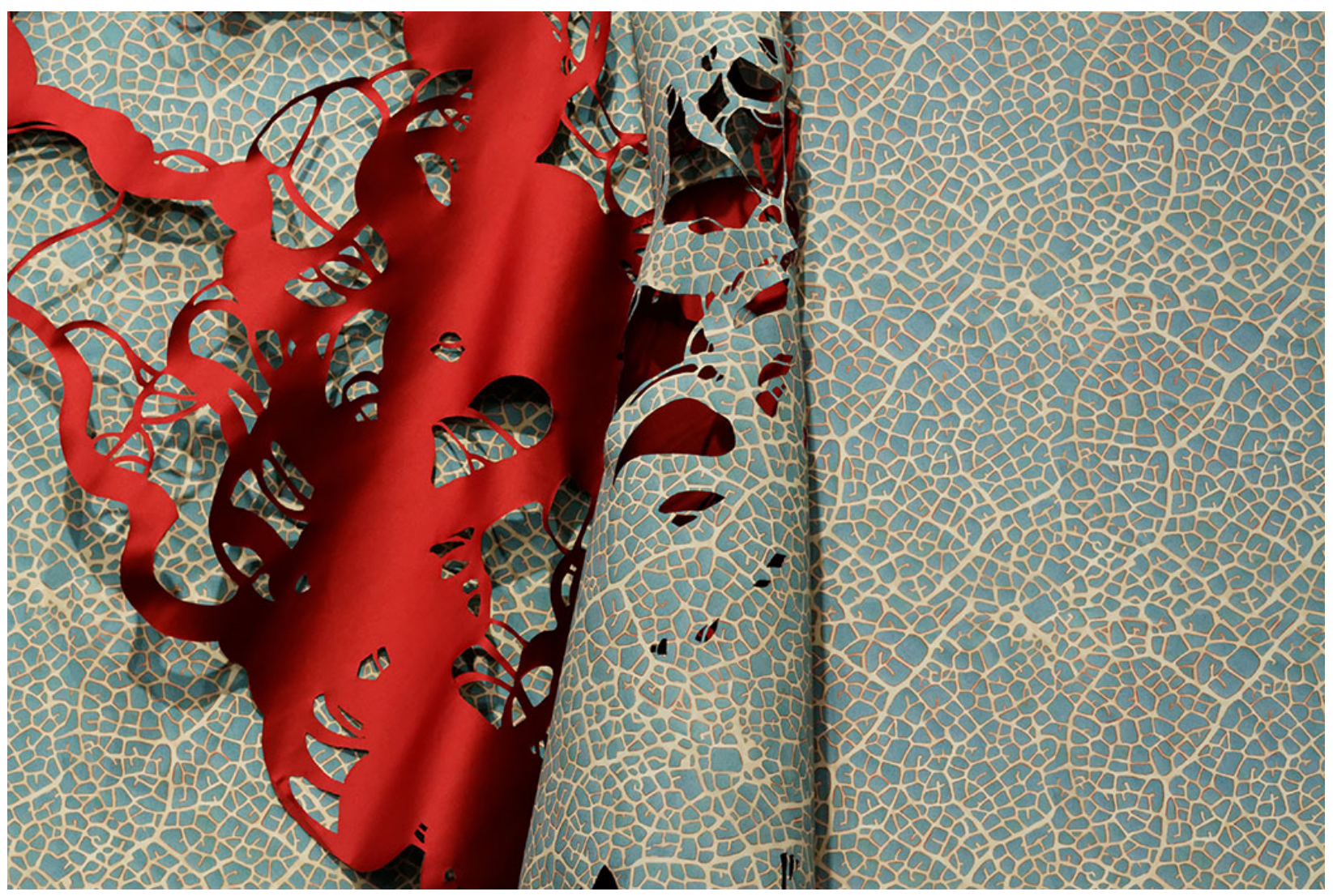

I moved to Iowa in 2001 to train as a hand papermaker at the University of Iowa Center for the Book, working with Timothy Barrett.

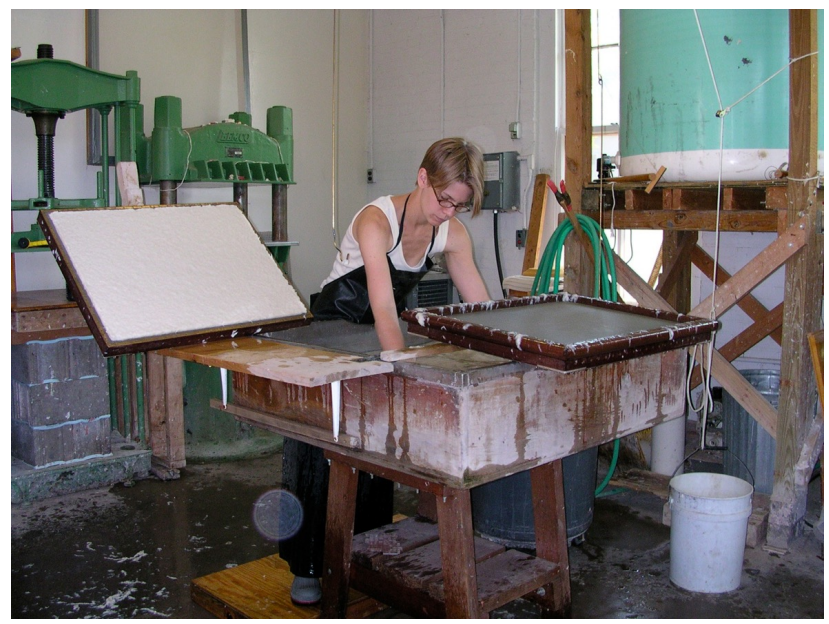

As a papermaker, I wanted to try translating this repeating 'leaf vein' image into overbeaten abaca, a fiber that works well for blown-out stencils, but also has an incredibly high shrinkage rate. I wanted to see what sculptural forms this process would develop if the paper was dried on fabric, pulling and 'drawing up' the fabric as it hung on a wall. 


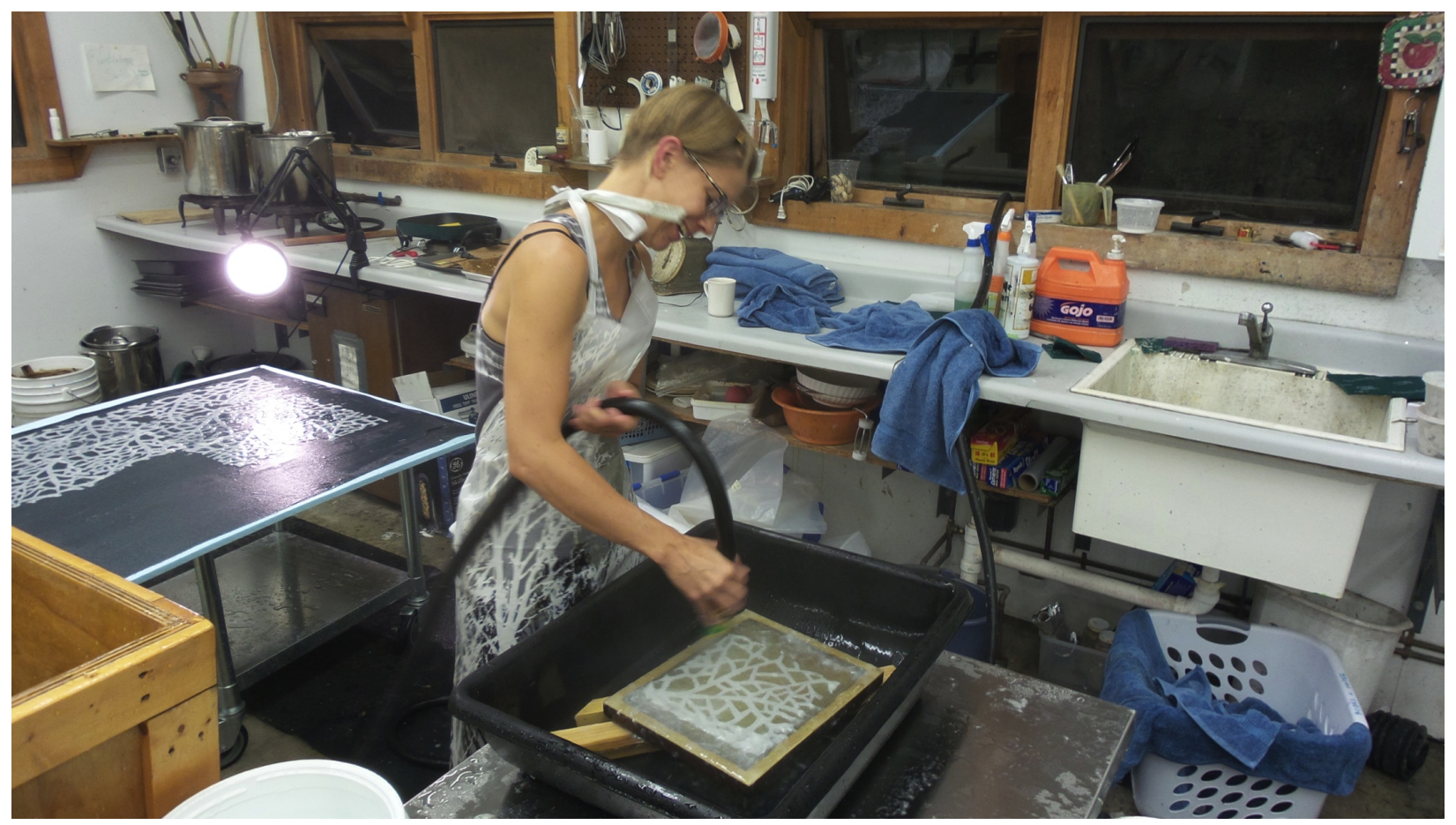

Here I am testing the process on a mold at Penland School of Crafts...

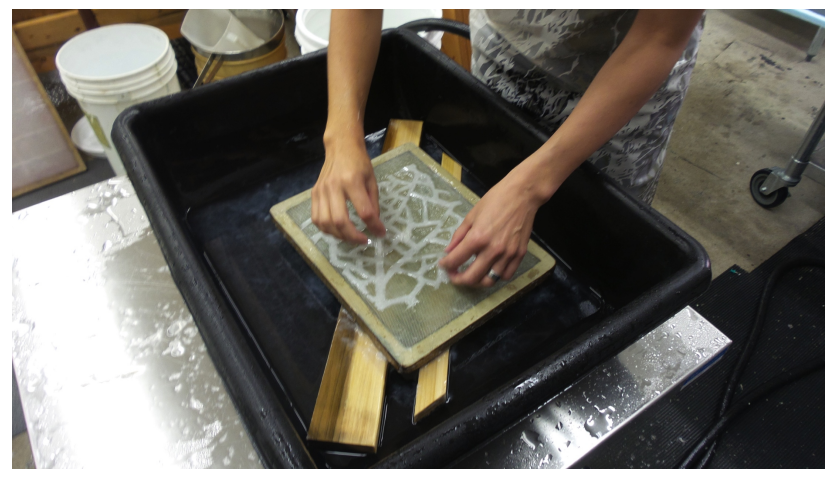

and couching it onto silk... 


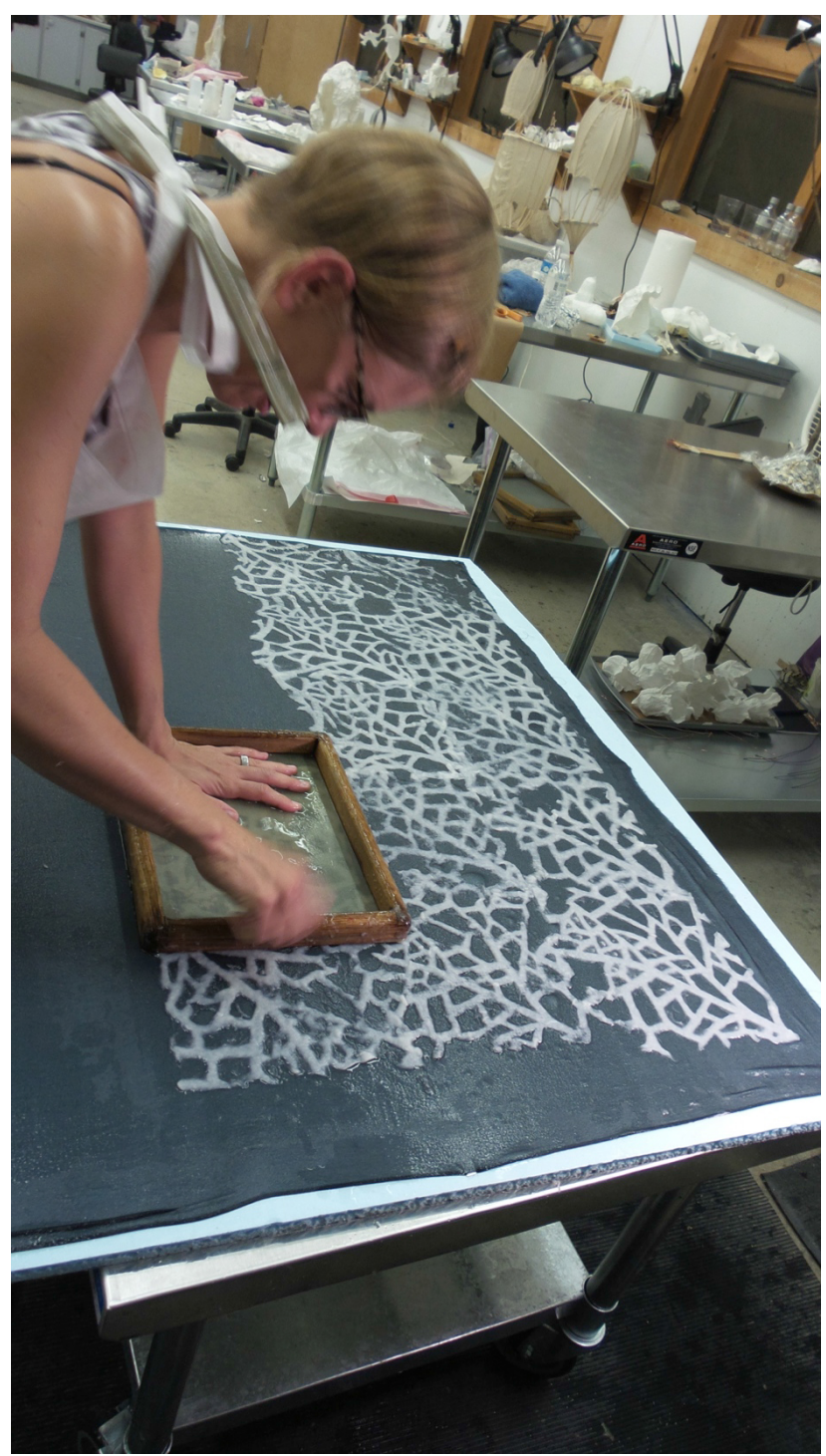

Since the change in the shape of the paper occurs during evaporation, I wanted to 'make the water visible' during the process. I decided to try using cochineal dye:

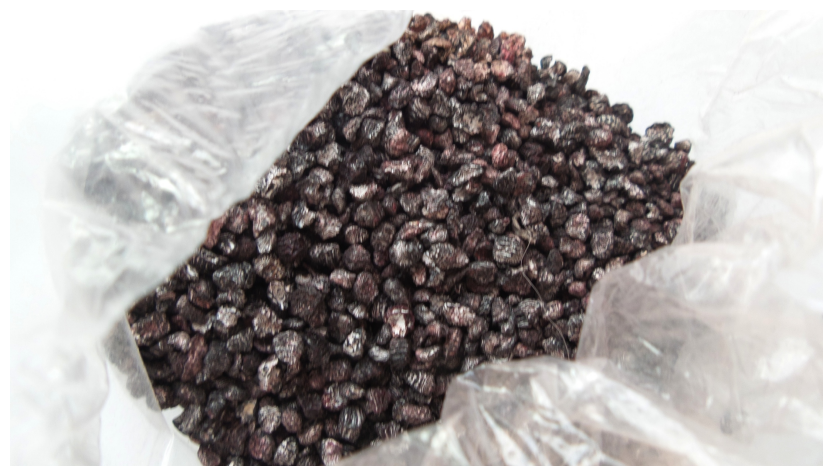

These bugs, when soaked in water, release an incredible red pigment... 
SUS-RURI: Proceedings of a Workshop on Developing a Convergence Sustainable Urban Systems Agenda for Redesigning the Urban-Rural Interface along the Mississippi River Watershed held in Ames, lowa, August 12- Handmade Paper and the Landscape 13,2019

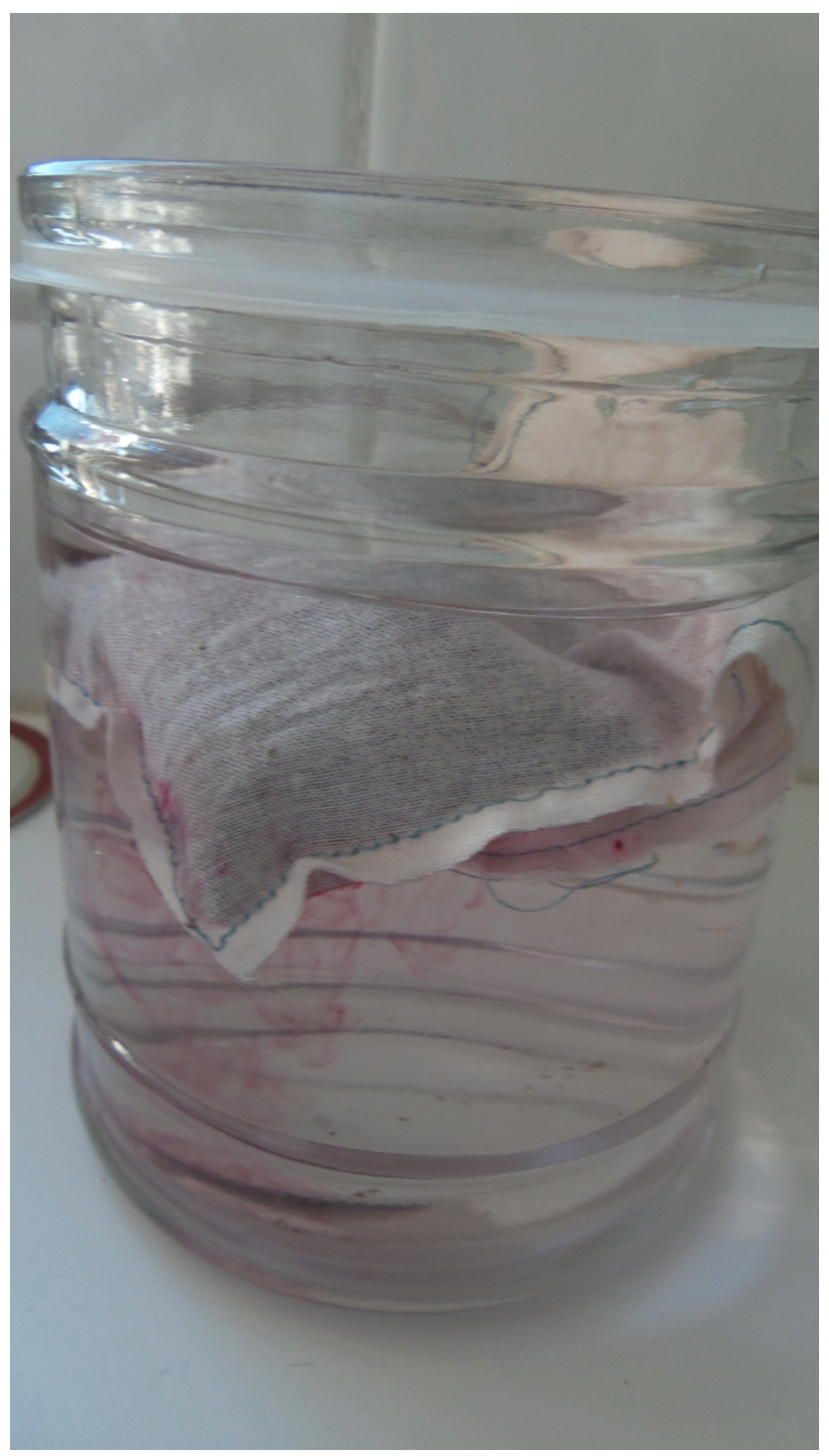

Here they are soaking: 


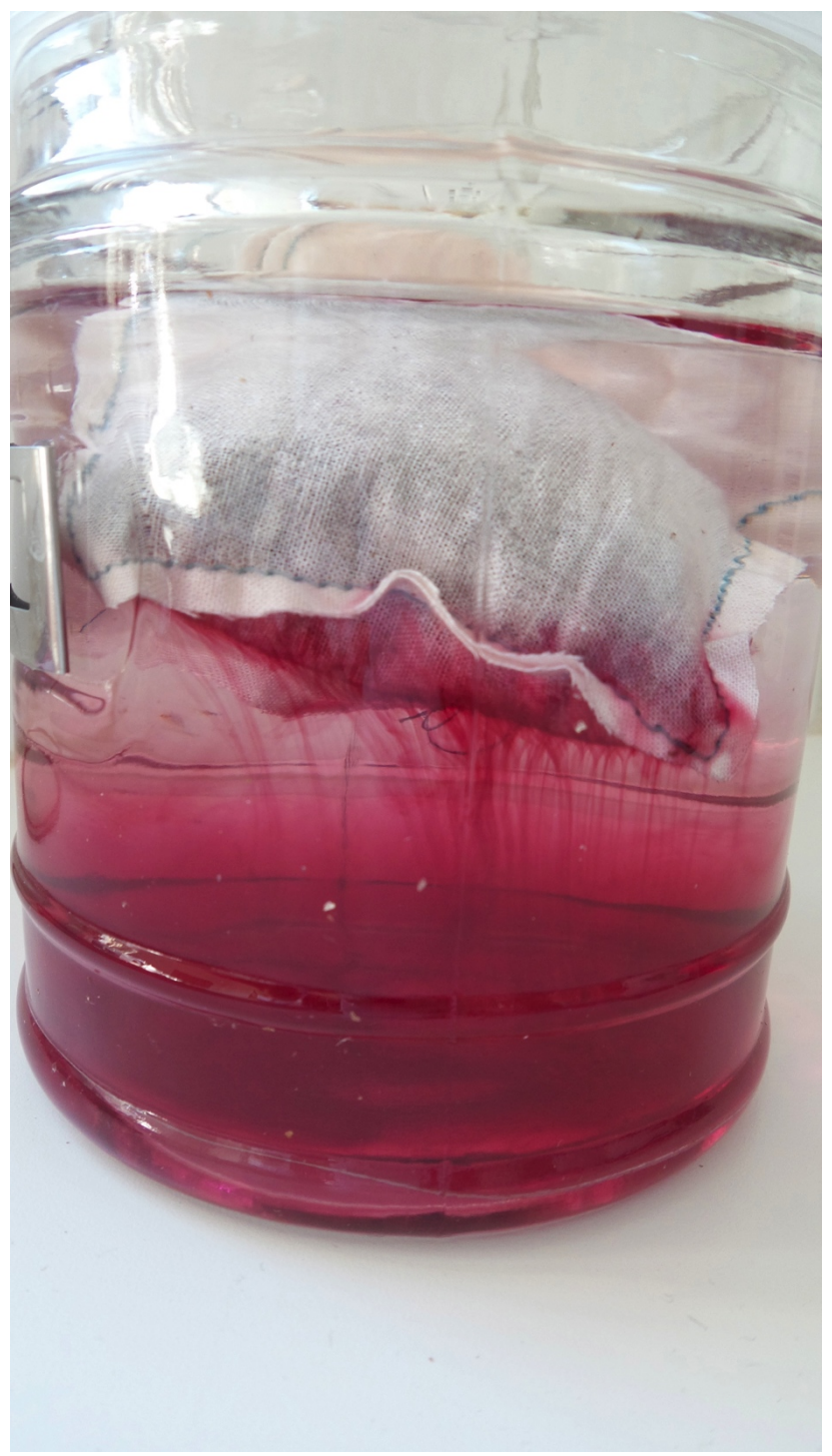

I dyed 25 yards of muslin with cochineal:

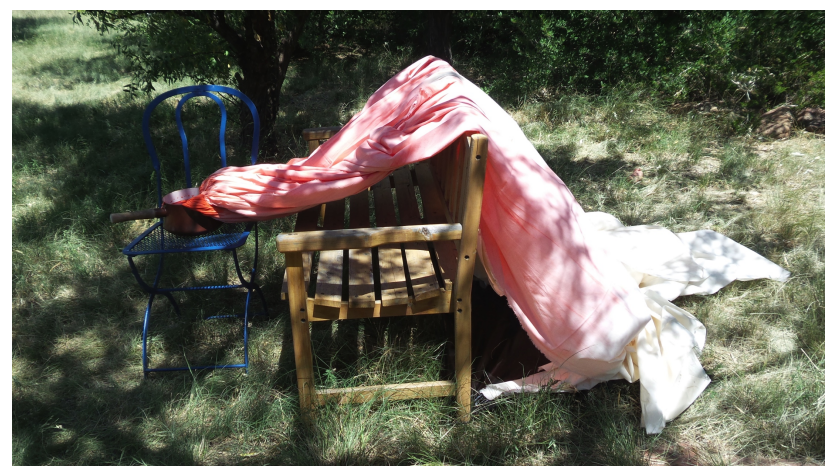

Here, the fabric is soaking up the dye... 


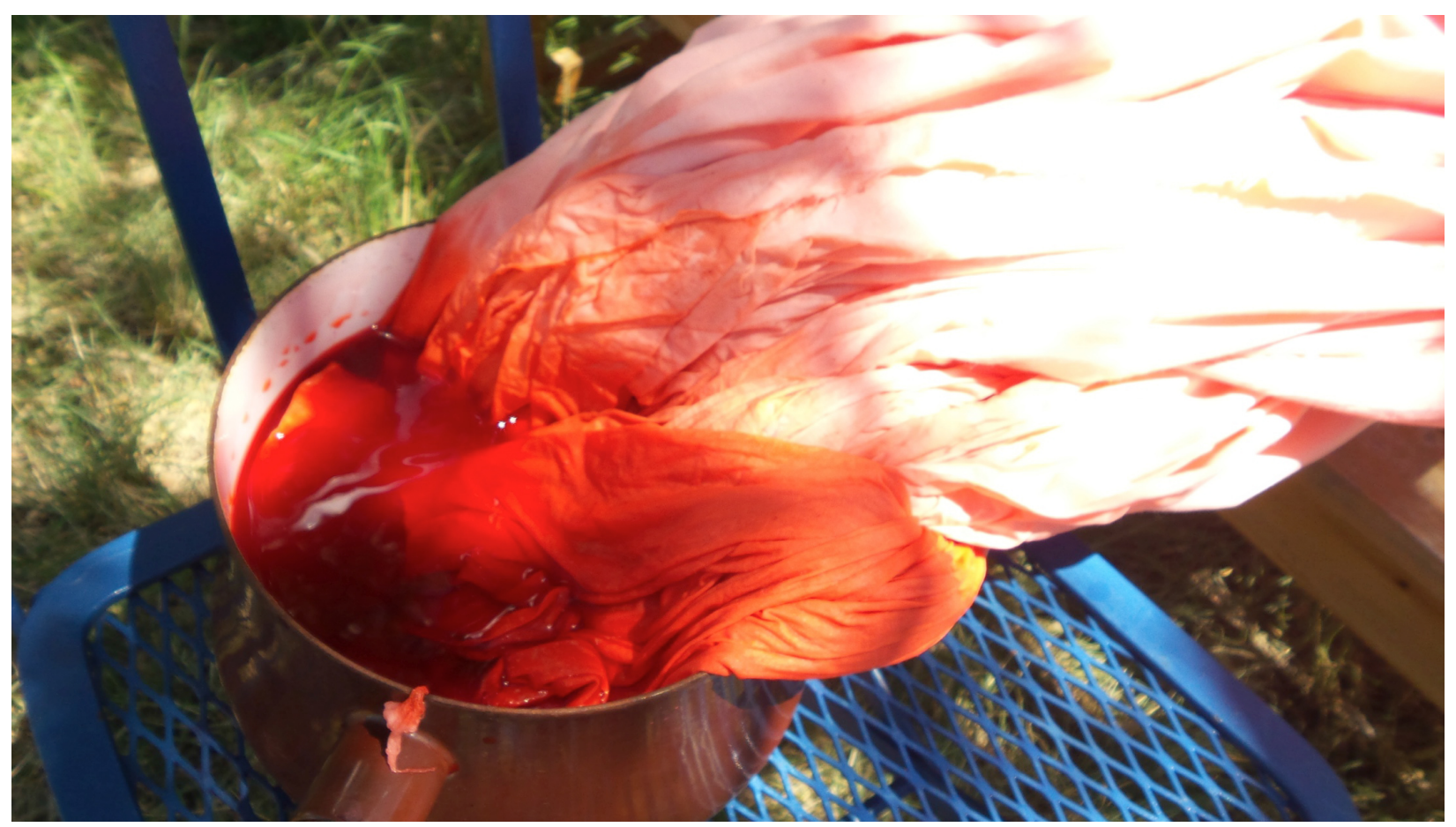

The dye changes from a grape juice color to a bright orange color based on the $\mathrm{pH}$ of the water:

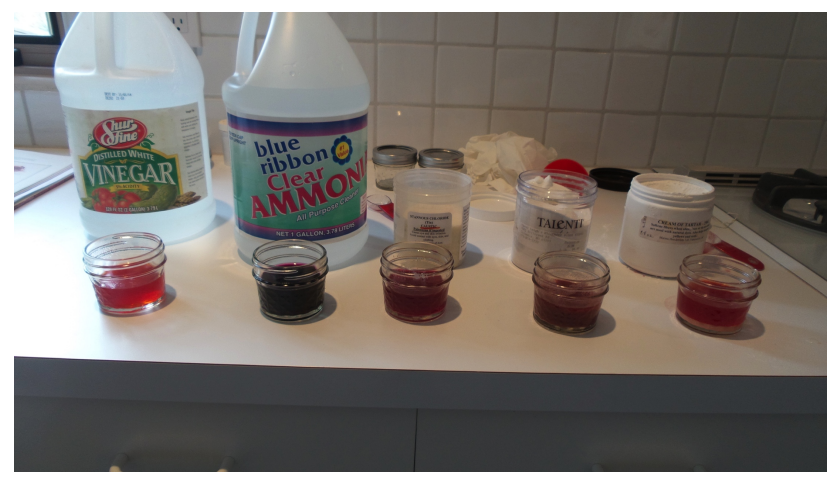

Here is a middle pink...

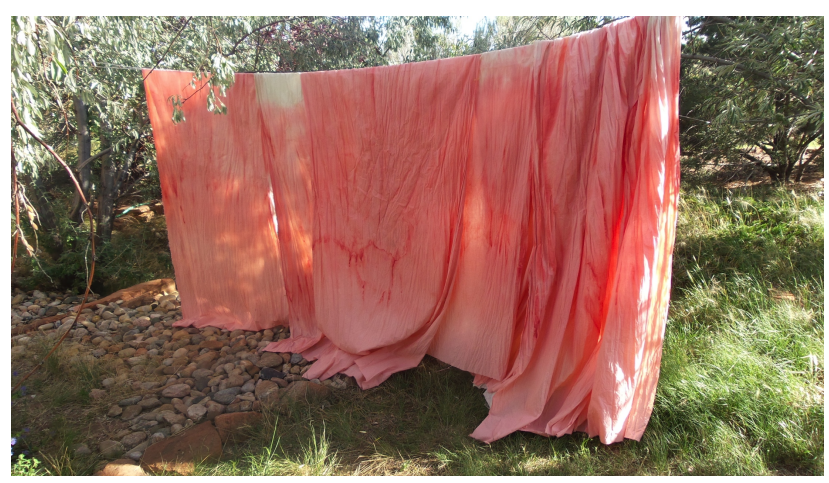


The dye isn't 'retained' by the fabric, and so it will move again when activated with water...

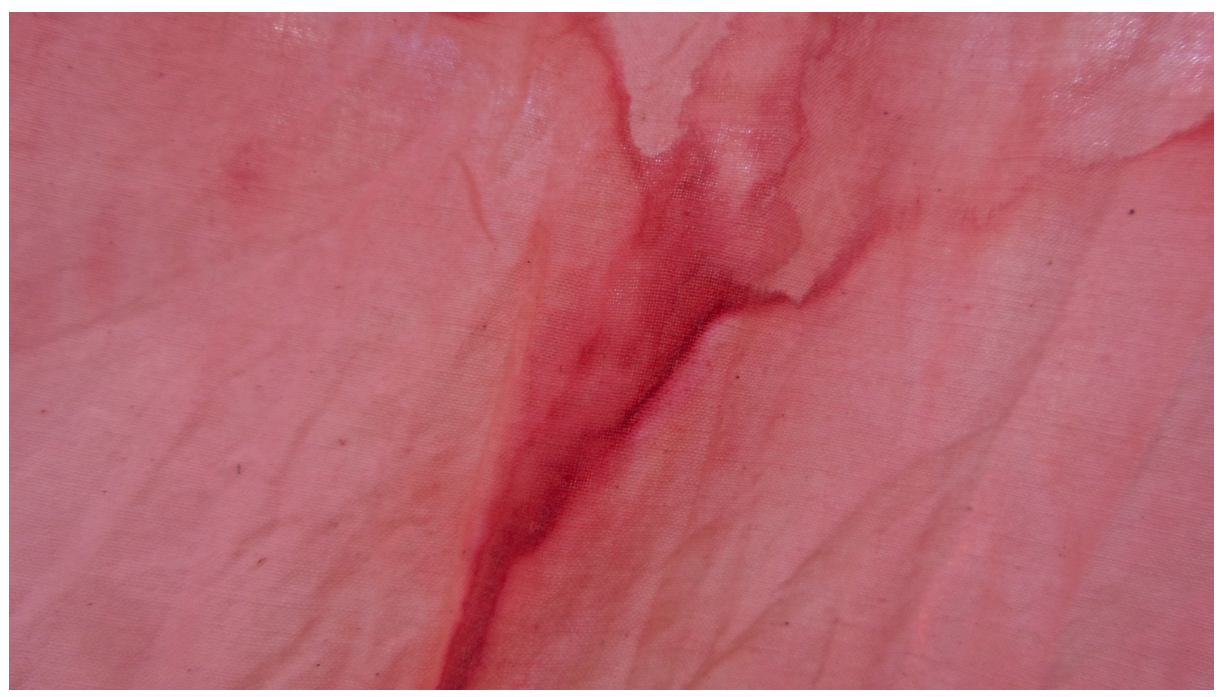

I installed the fabric directly on a $10^{\prime} \times 27^{\prime}$ wall:

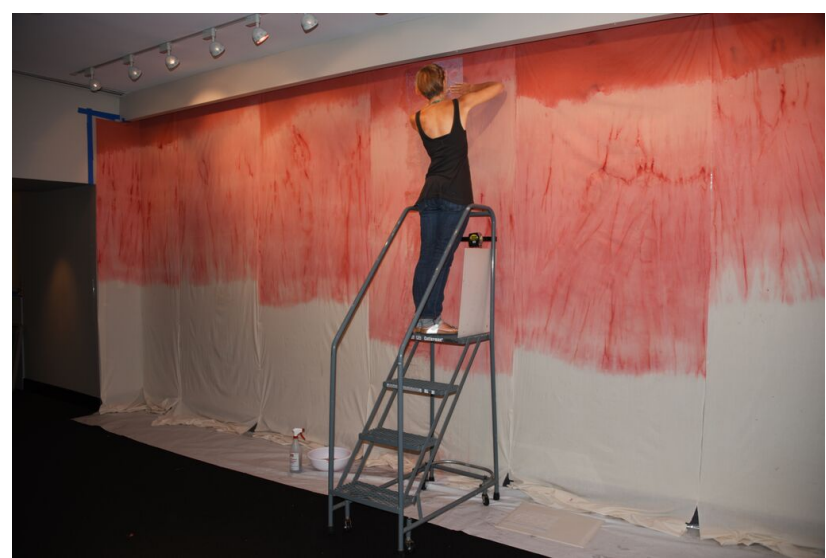

At the Robert C. Williams Museum of Papermaking at Georgia Tech I worked with students, to create the piece "Watercourse" for the exhibition "Paper Narratives" in 2015: 


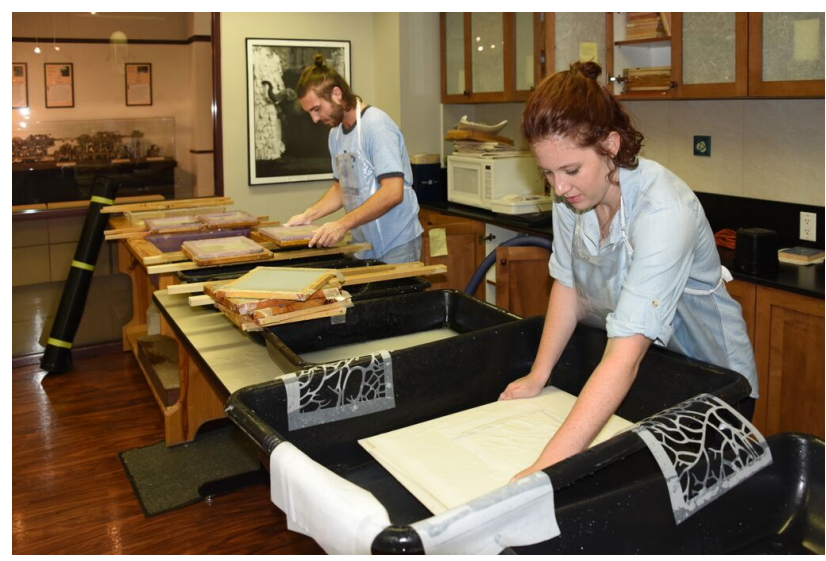

Here we are forming the 8 x 8 inch sheets:

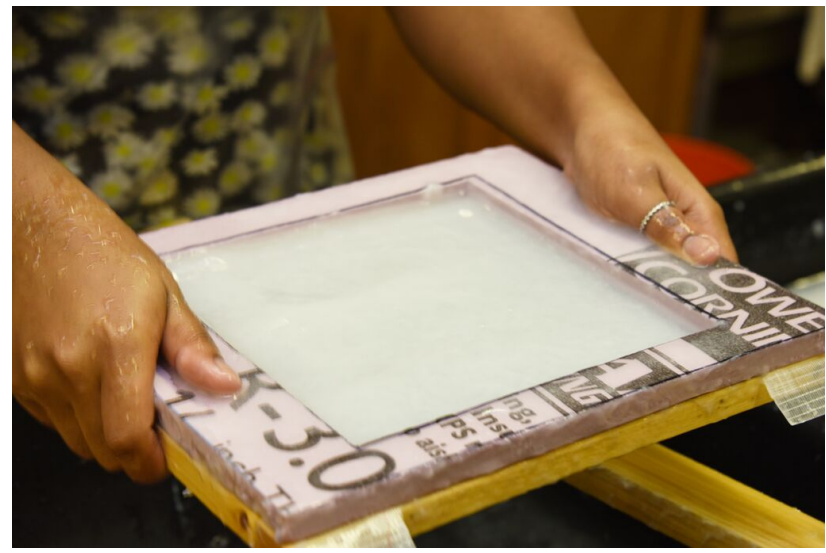

We used a process of applying a stencil to a freshly couched sheet...

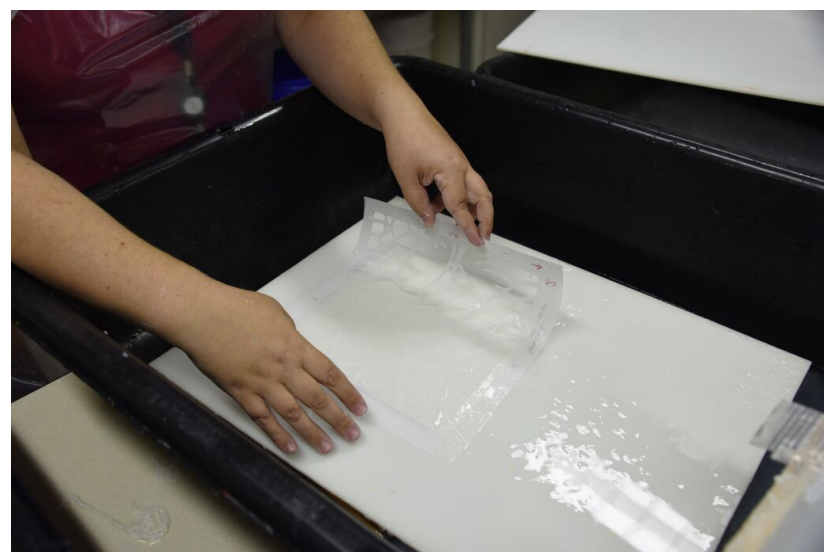

Then blowing out the stencil... 




Removing the stencil...

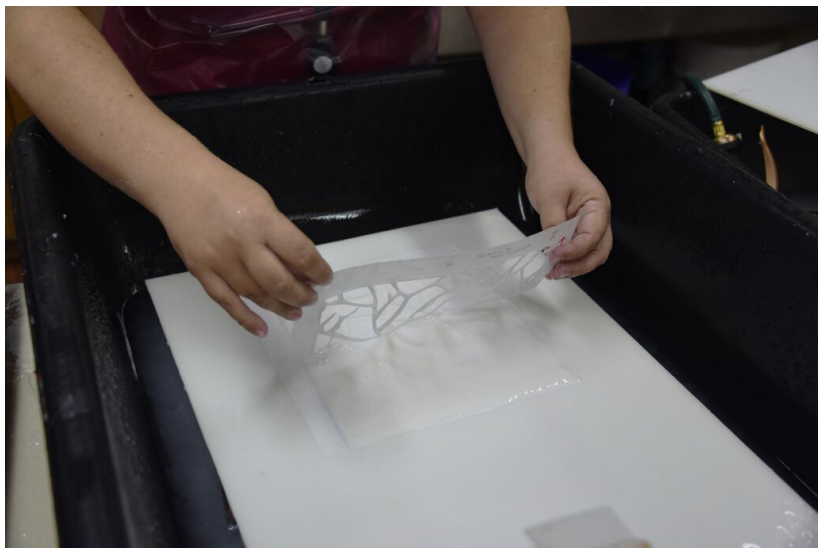

And applying the abaca directly to the fabric covered wall:

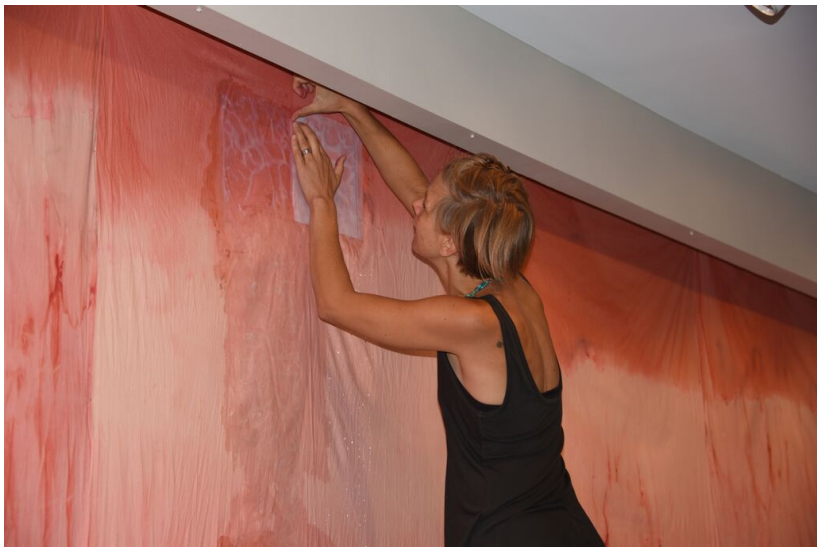

To create a repeating pattern moving down the wall... 


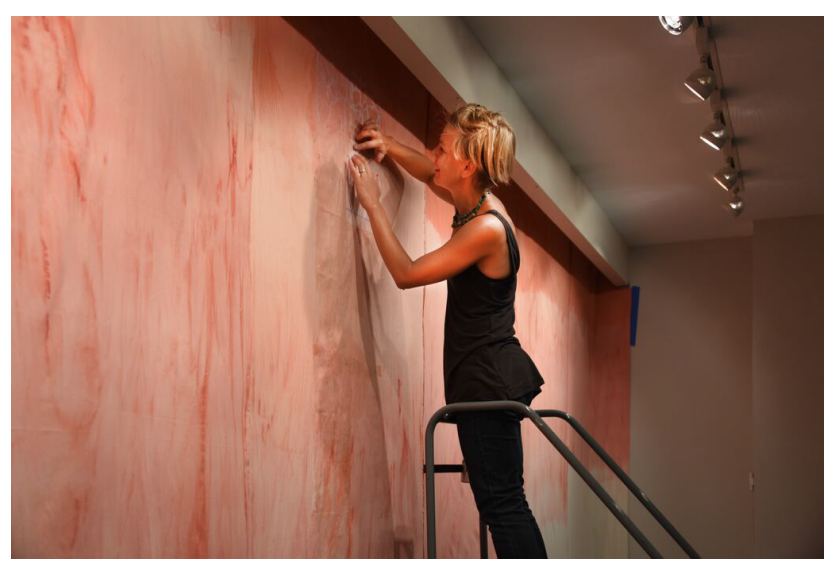

Here is an older stencil on the right (it is starting to absorb the dye) and a newer one on the left...

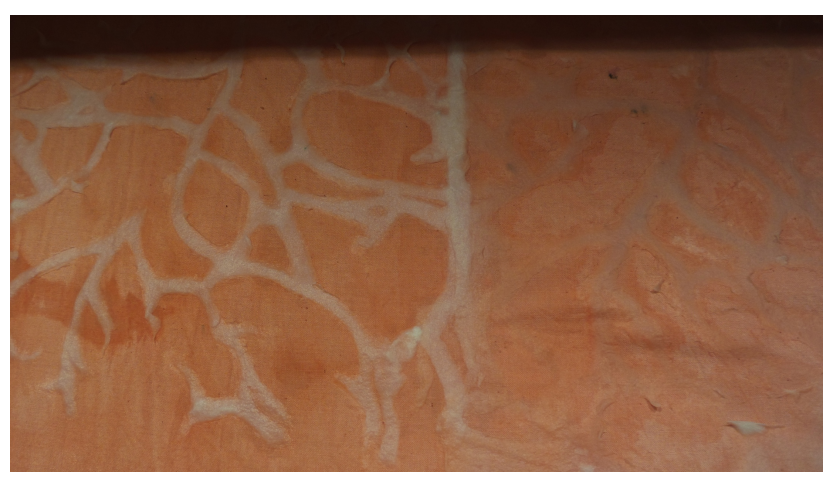

At the bottom of the wall the paper 'carried' the dye from the top of the wall: 


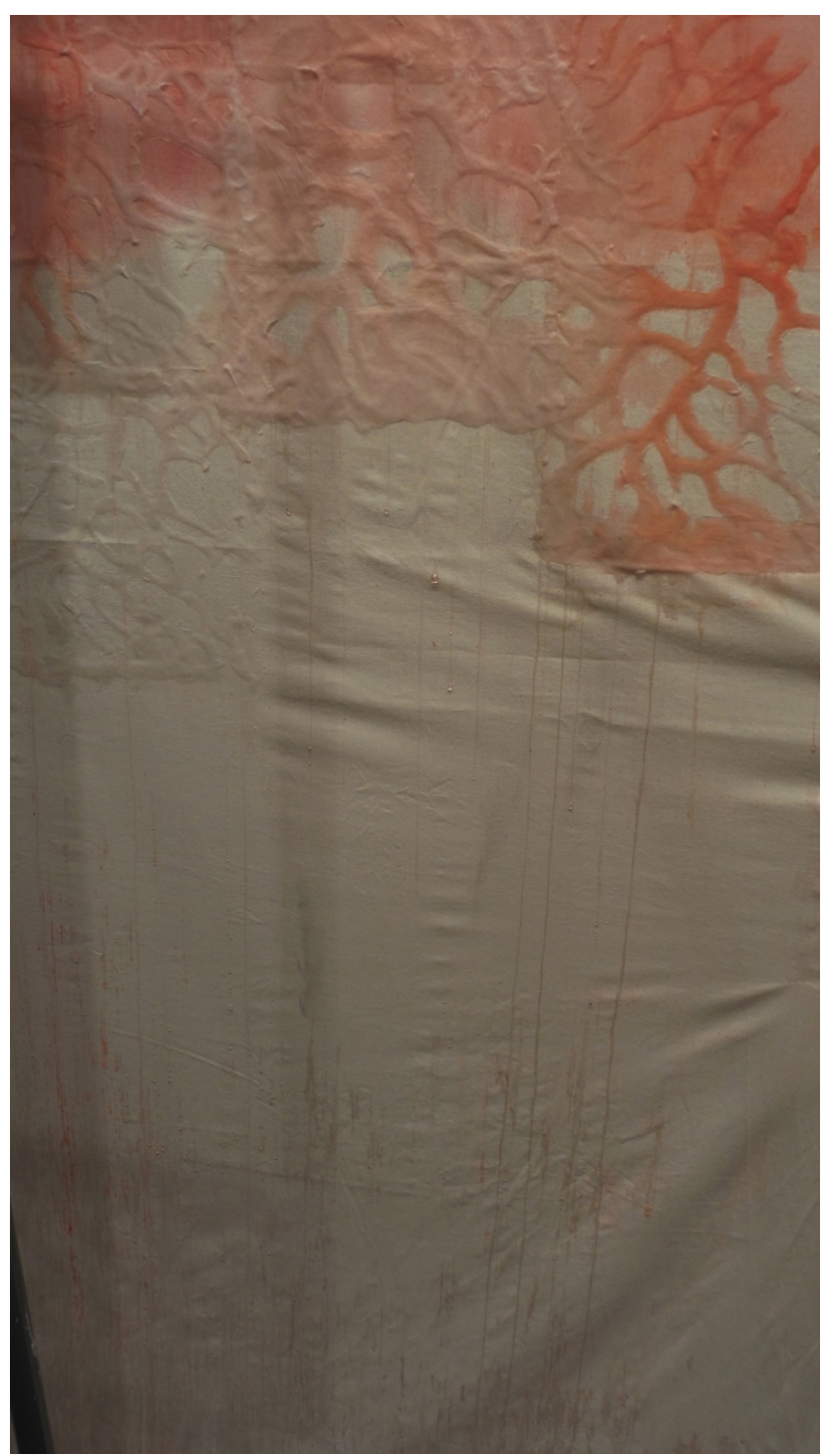

Here the paper is drying and drawing up the fabric... 


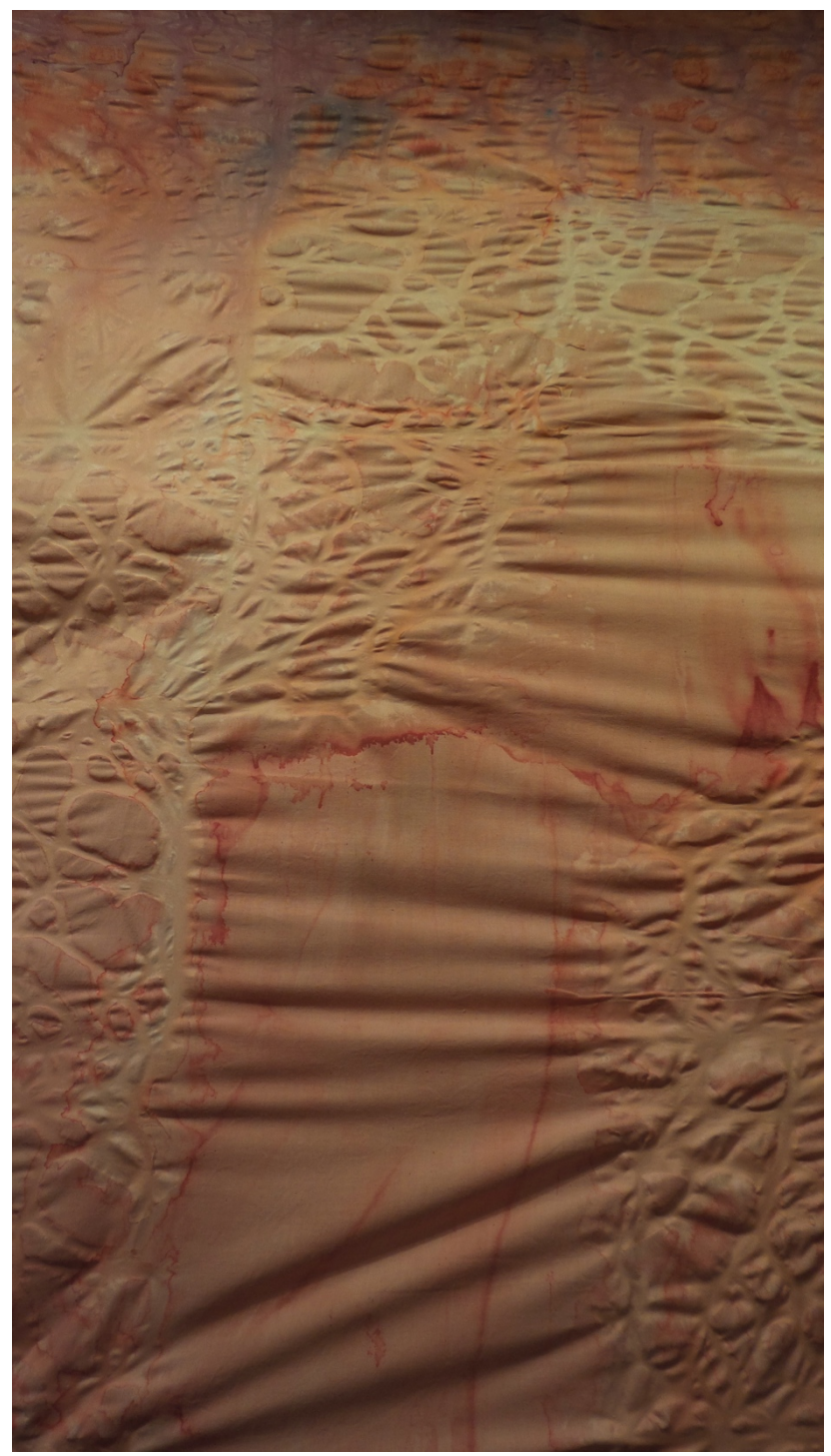

The finished piece, named "Watercourse," was removed from the wall after it dried and hung from the soffit... 


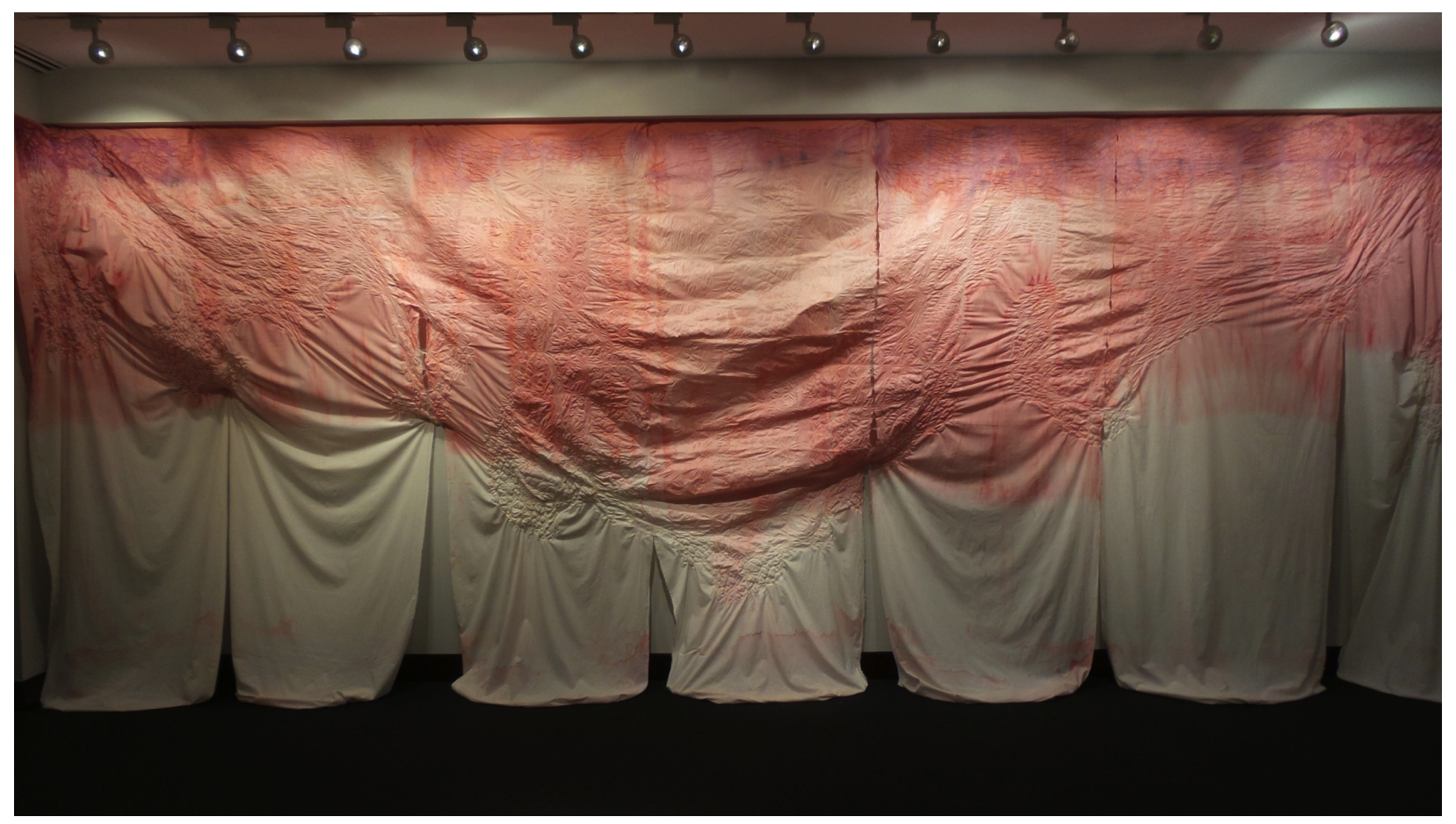

Watercourse, 2015

Muslin, Cochineal, Abaca, approx. $24 \times 12$ feet

This is a close-up showing detail: 


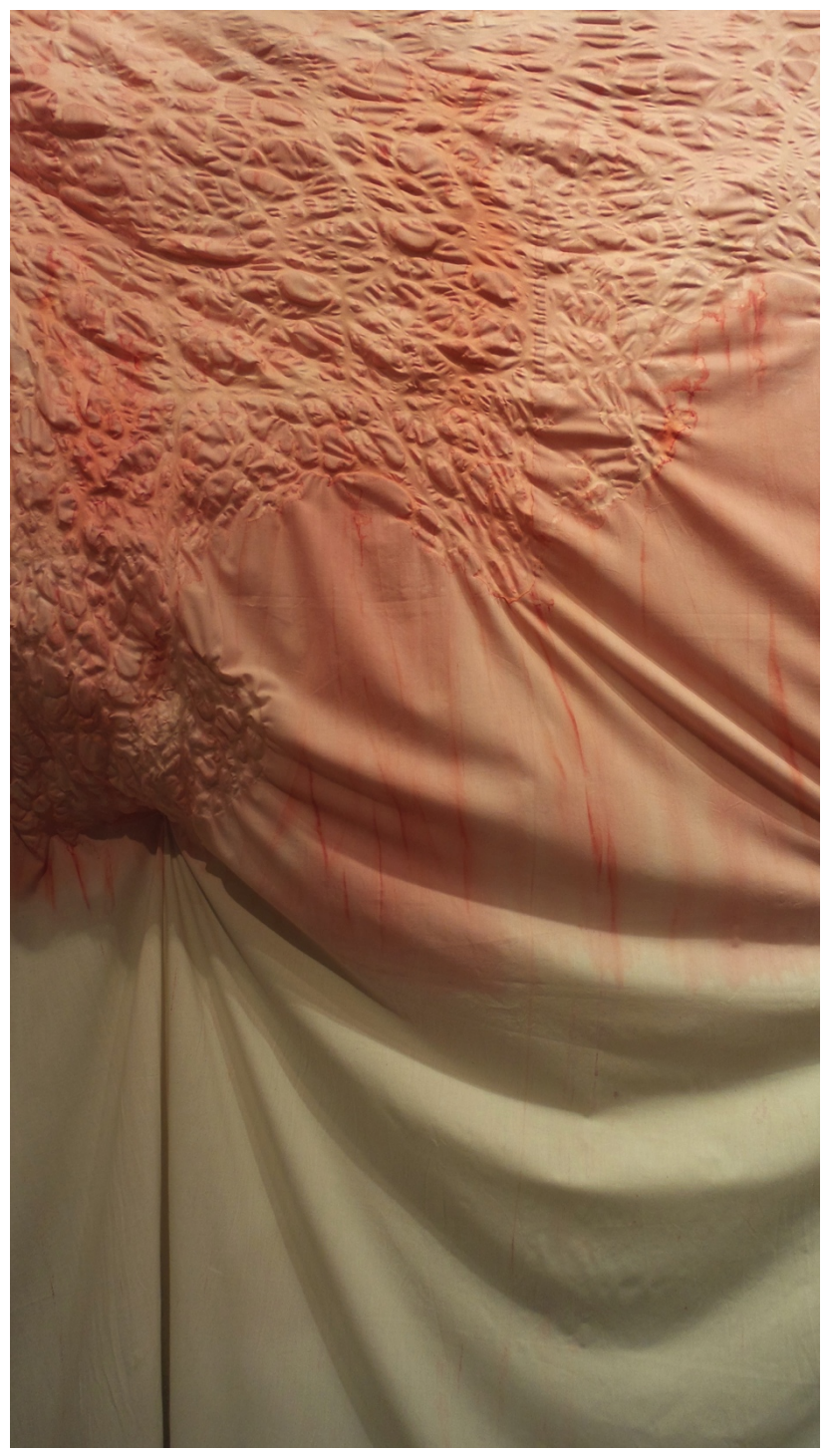

The top of the wall turned purple because of the $\mathrm{pH}$ of the water... 


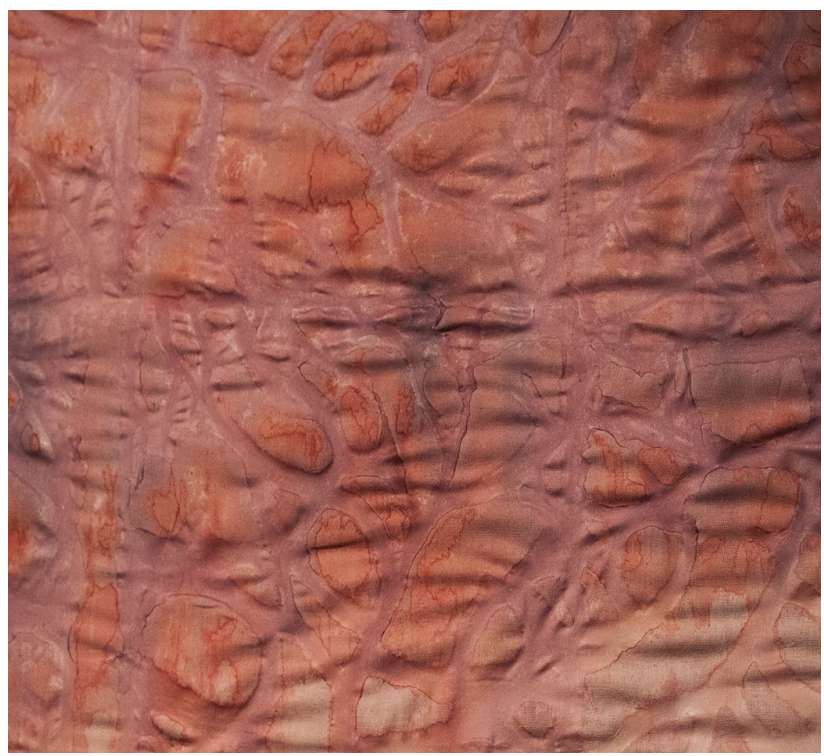

And the abaca was strong enough to span the breaks in the fabric yardage:

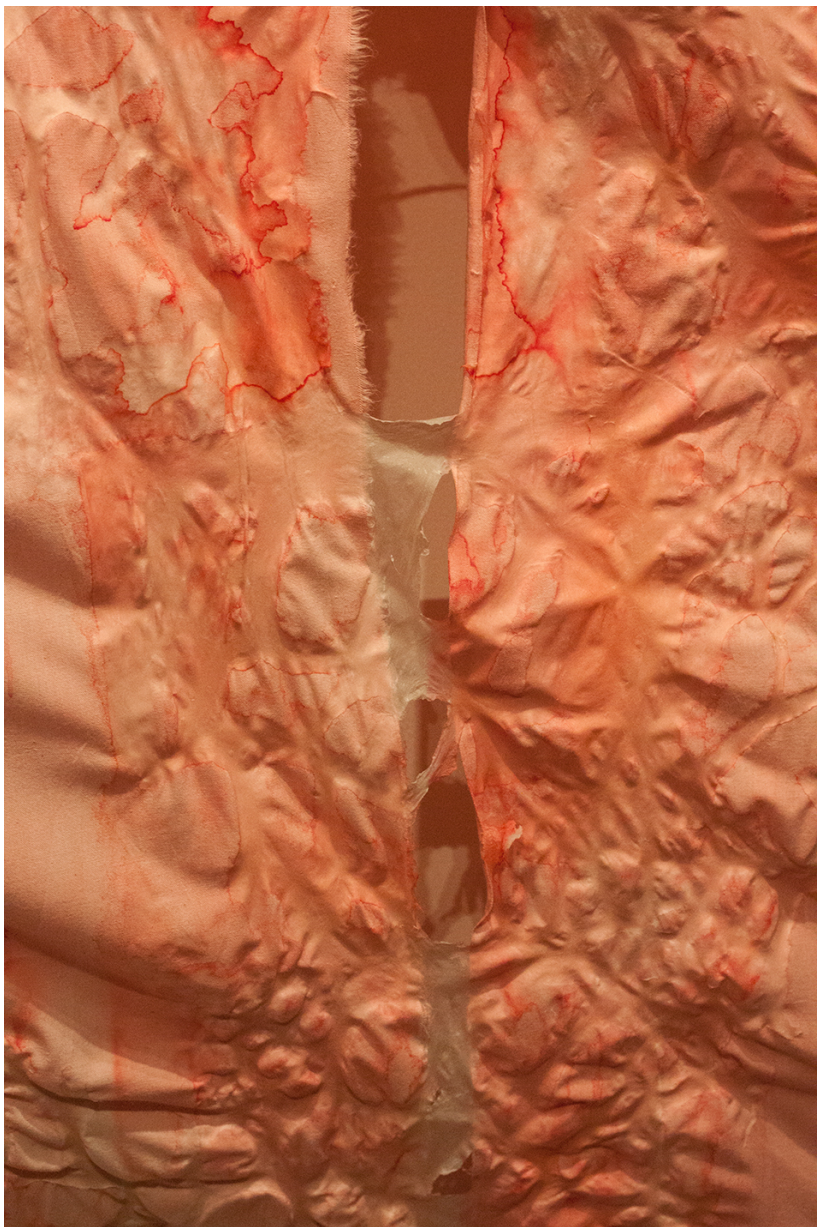


In 2018 I was asked by the Dubuque Museum in Iowa to design a site-specific work for the exhibition "Paper, Material as Message." I wanted to use the Mississippi River as my subject, and began with these historical maps of the Mississippi before it was channelized by the U.S. Corps of Engineers:
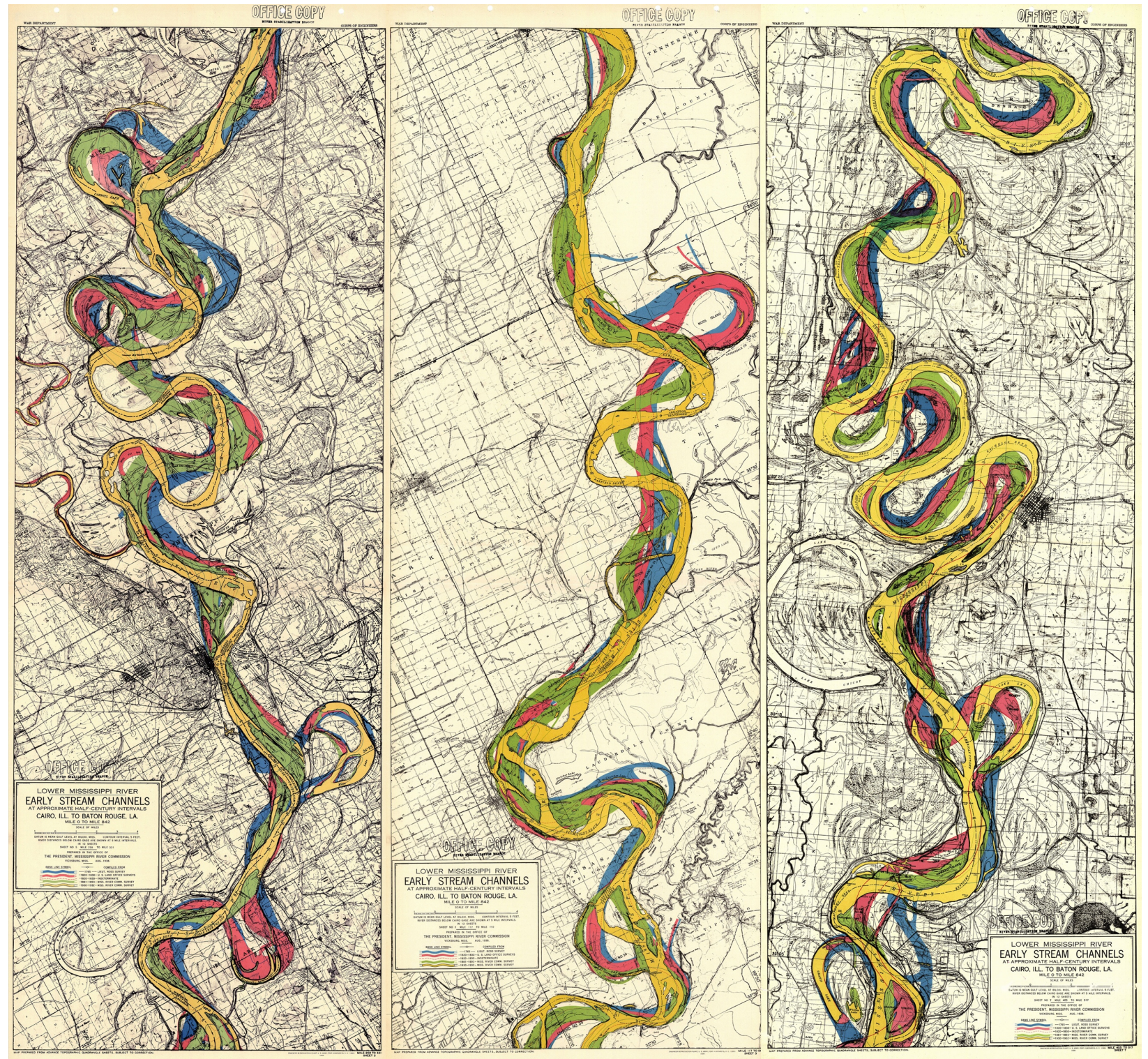

Here is the map, separated into sections, to fit on a $28^{\prime}$ by $8^{\prime}$ wall at the Dubuque Museum of Art.... 




Here is a digital map I made of a section of the river divided into the sheet size of the paper mold I was working on (4' x 8' ):

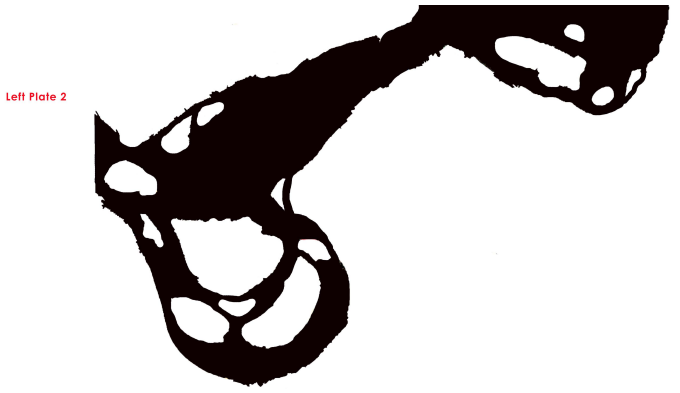

Here is a hand-cut stencil of a river section, cut out of silicone release paper, so that it can be used to form a wet sheet of paper... 


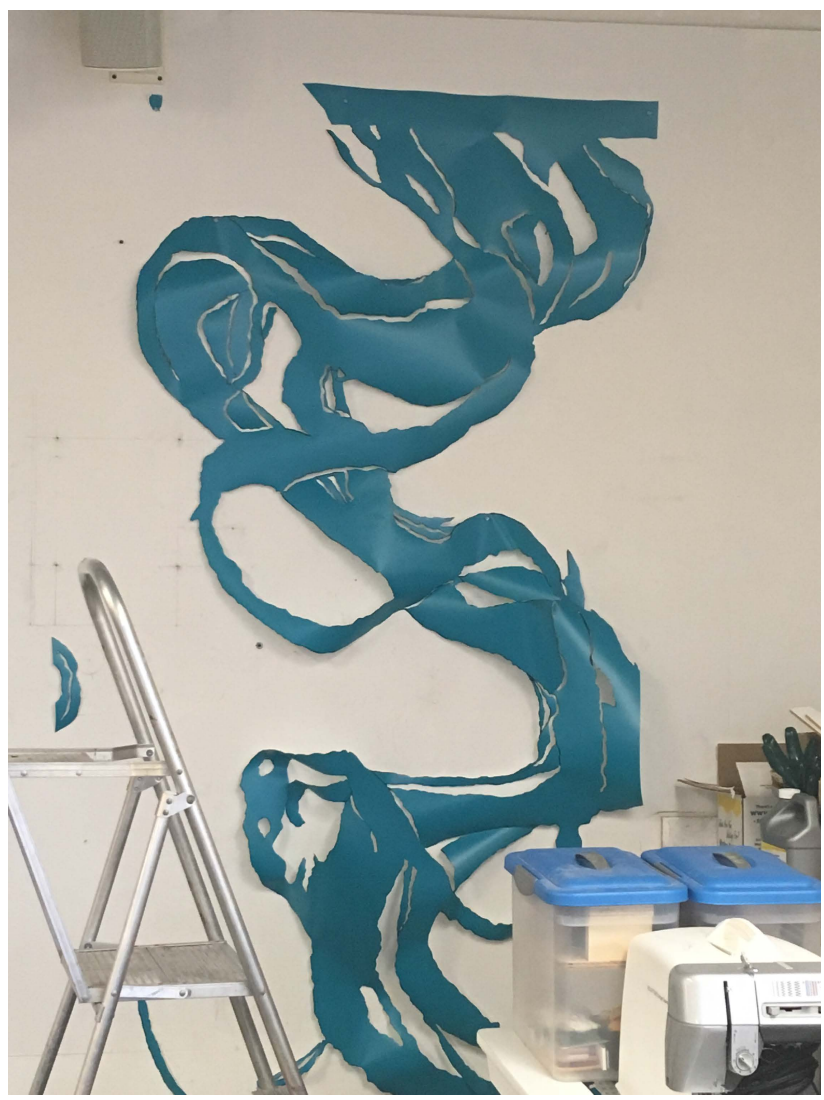

Here is the wet handmade paper in the shape of the river meander on a felt...

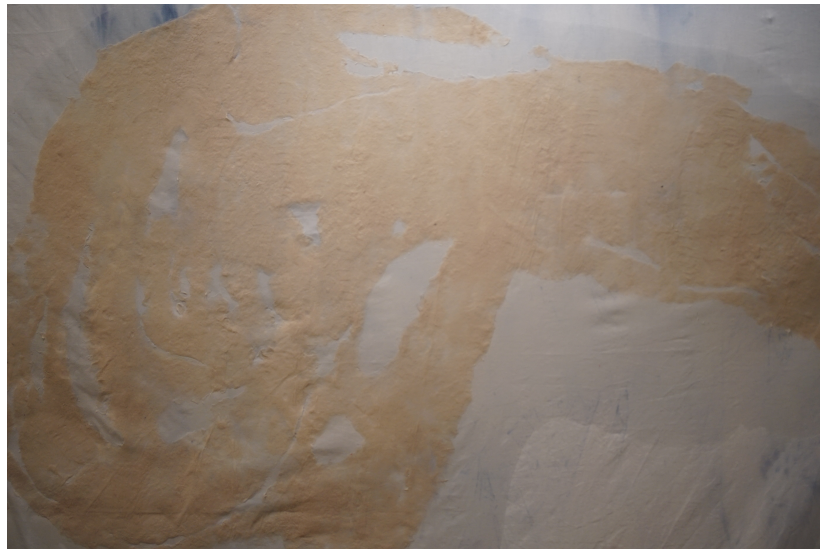

This is the wall in the Dubuque Museum prior to installation: 


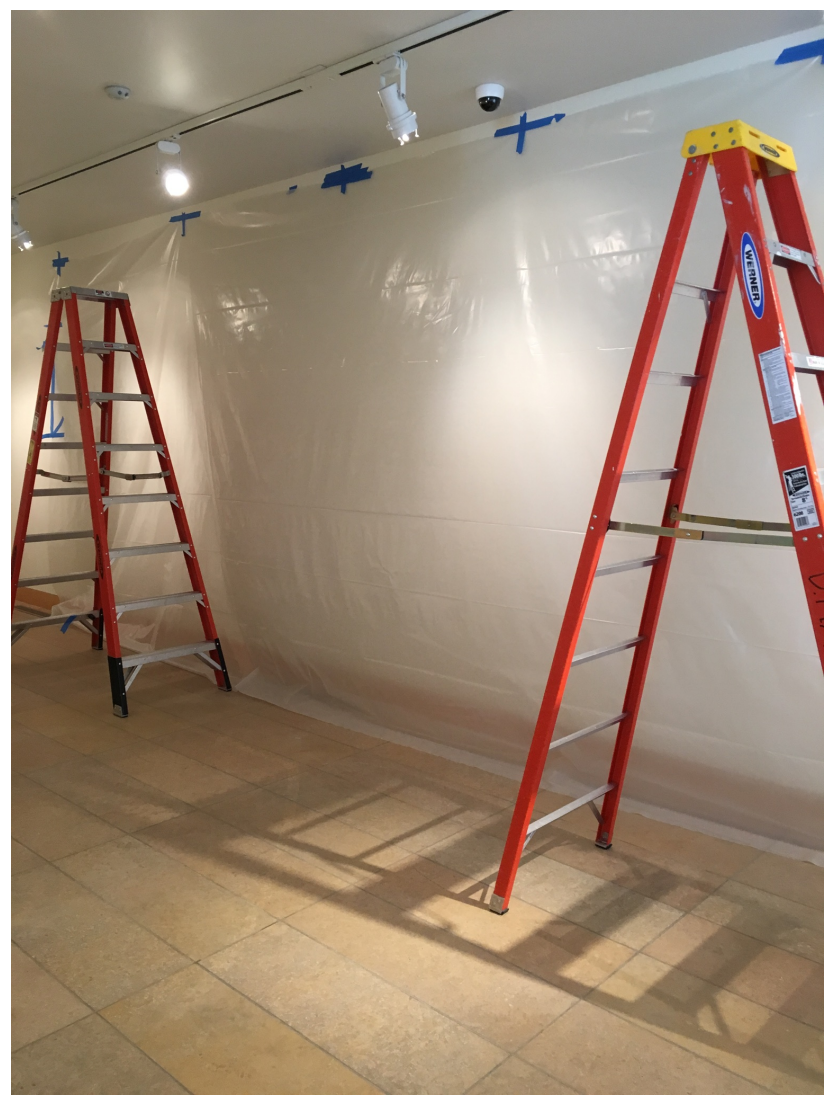

And dyed muslin fabric hung on the museum wall...

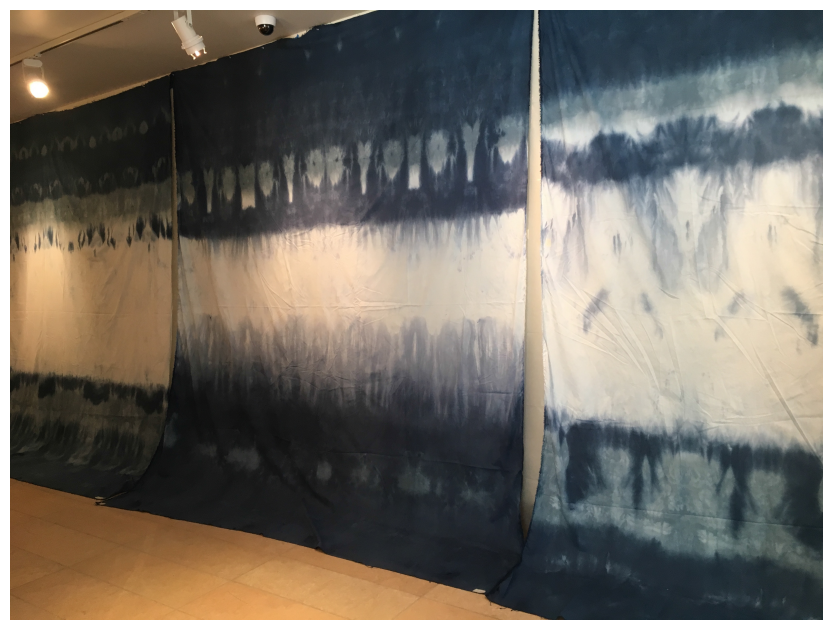

Here is the wet paper couched to the muslin fabric directly on the wall of the gallery: 


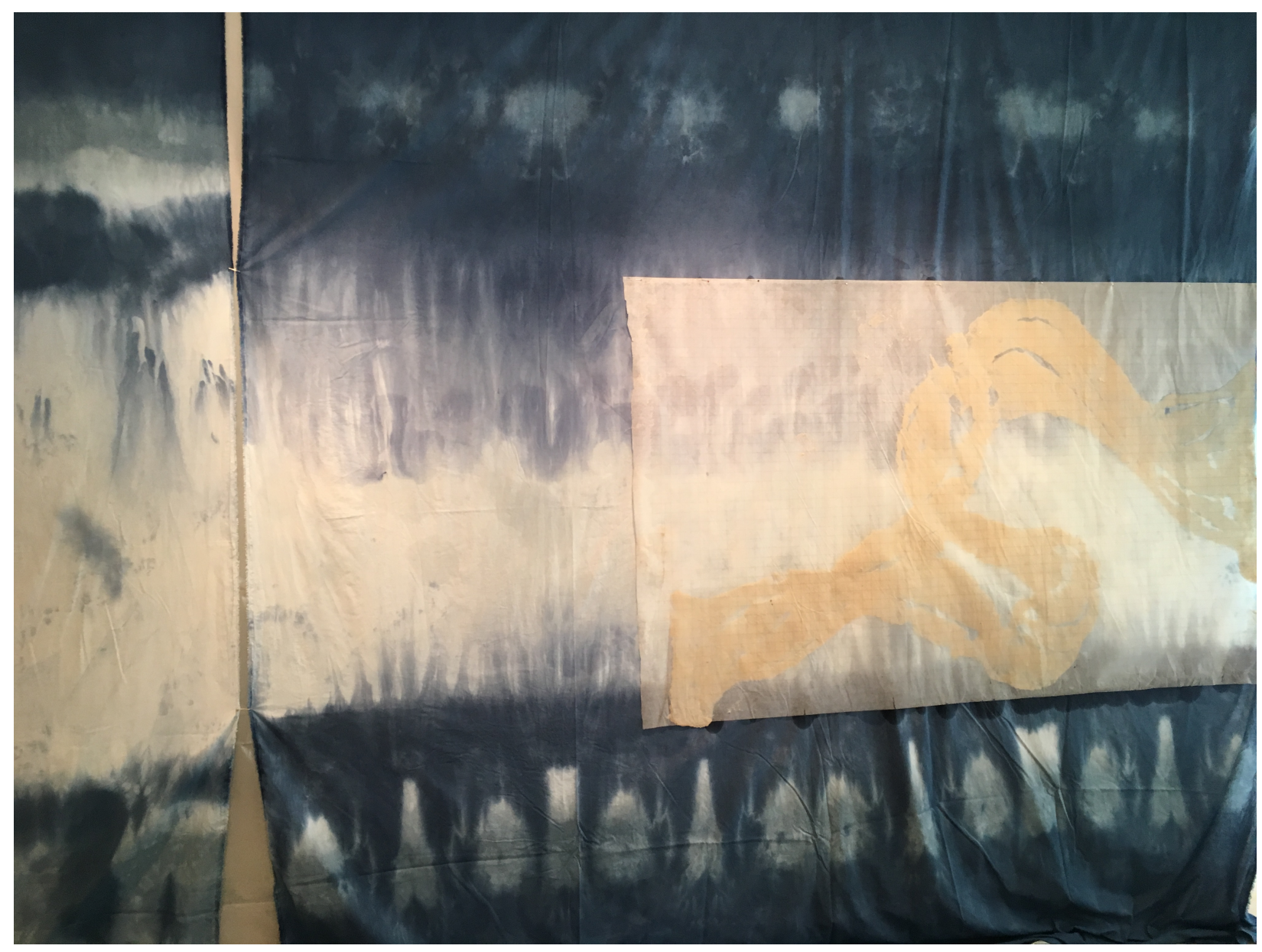

Below, I'm installing the work with a sponge, using water as the material that releases the paper from the felt: 


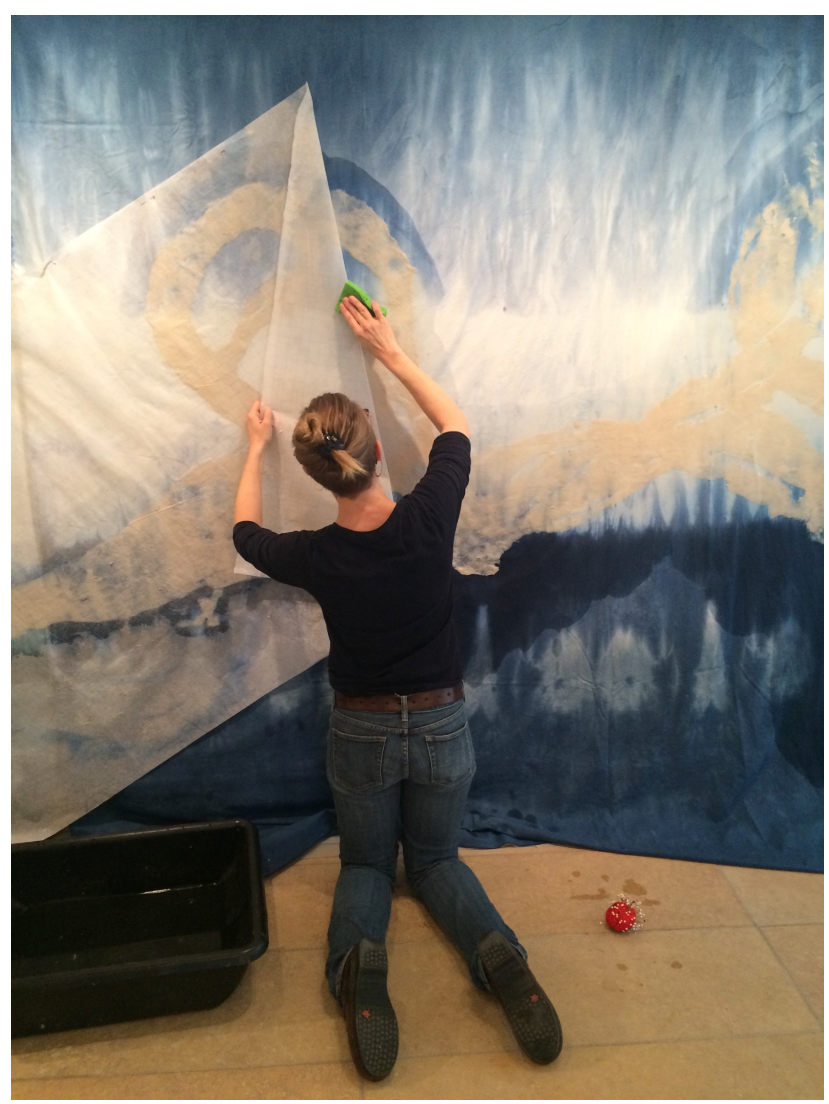

The water activates loose dye in the fabric....

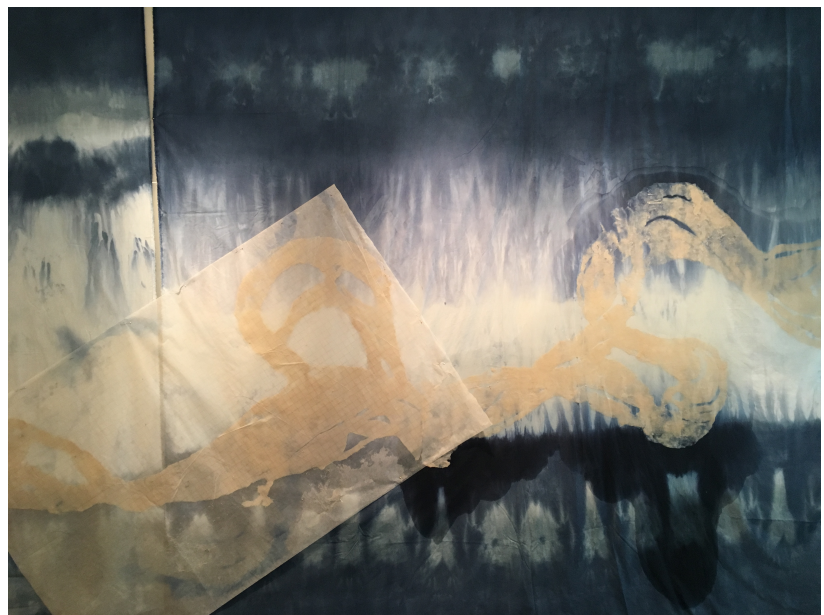

The re-introduction of water holds the paper and fabric together, and also impacts the handmade paper and the dye. Water moves the colorants into the paper, and down the wall: 


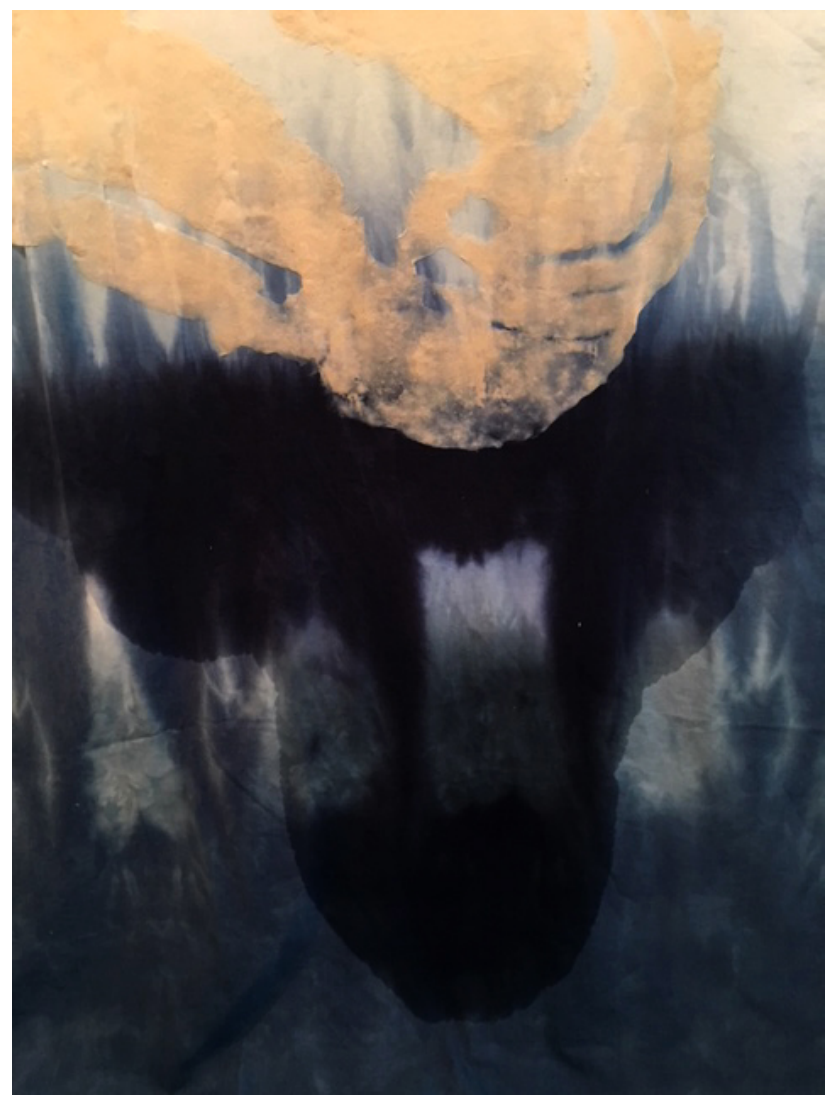

Here is detail of the process.... 


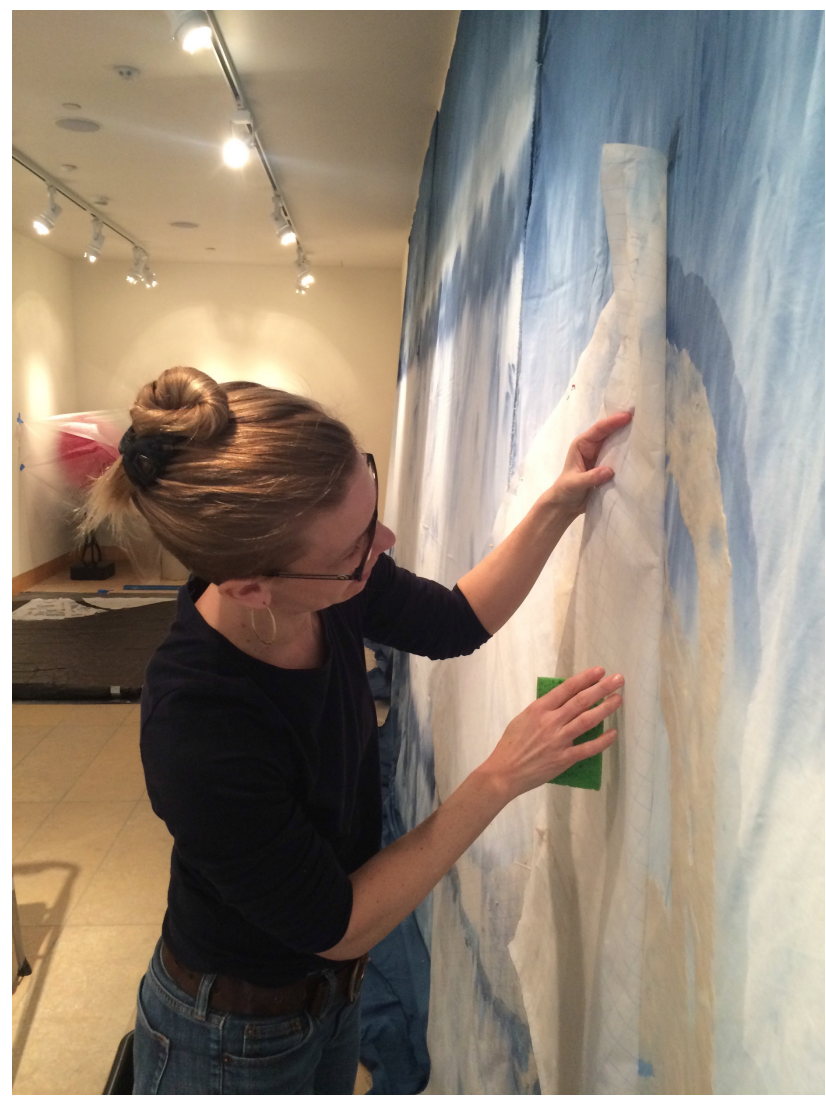

The abaca can shrink up to 60 percent of its original size:

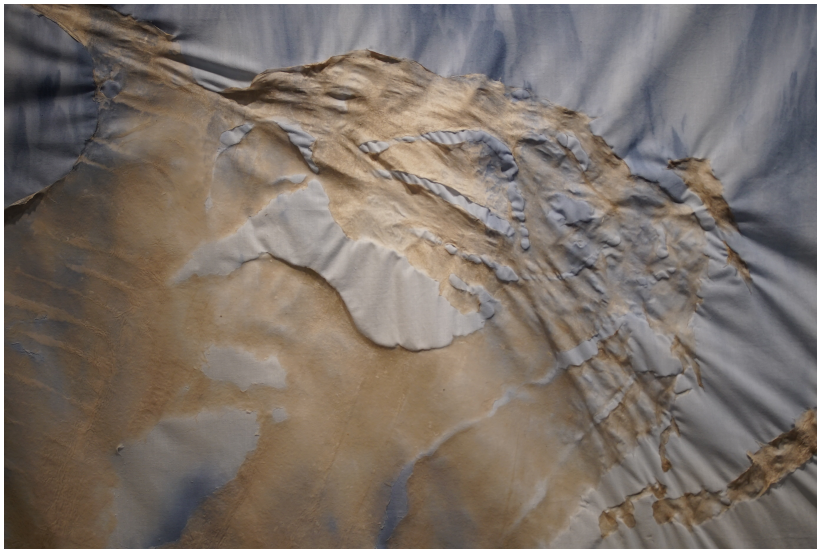

This is the paper dried onto the fabric... 


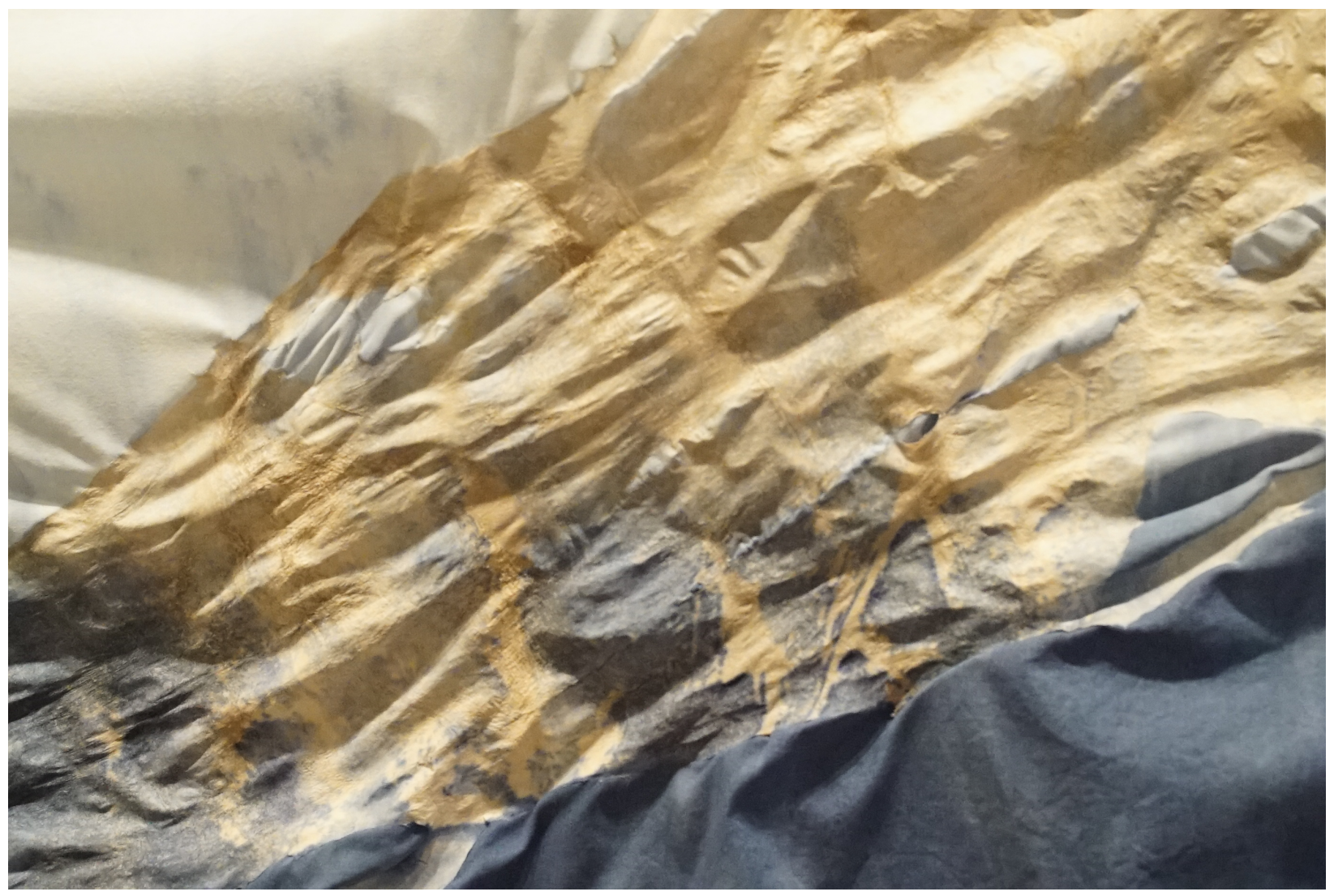

And as it dries it soaks up the color:

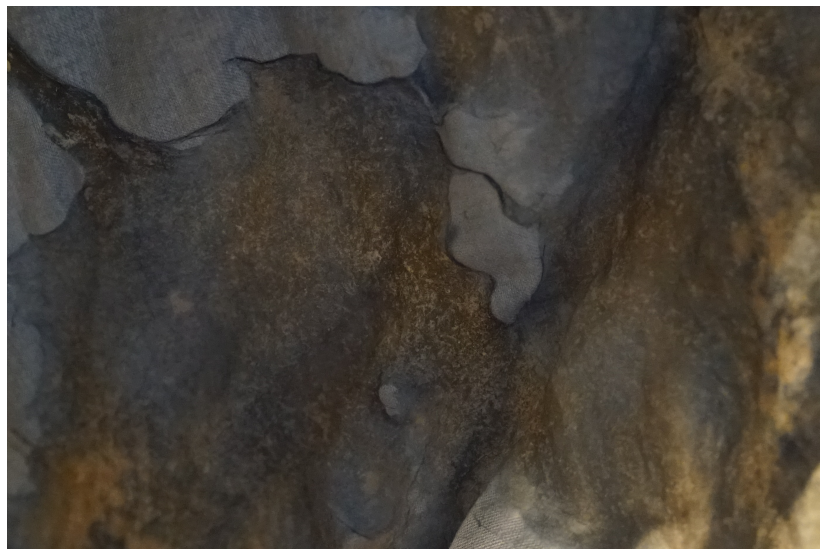

The abaca was strong enough to span the breaks in the fabric yardage... 


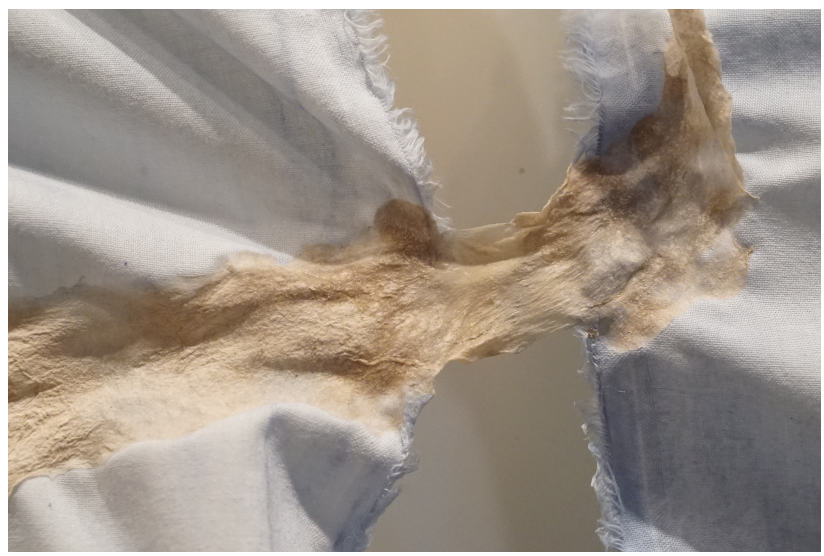

And the color of the paper naturally darkens as it shrinks, causing a topography to form in the fabric:

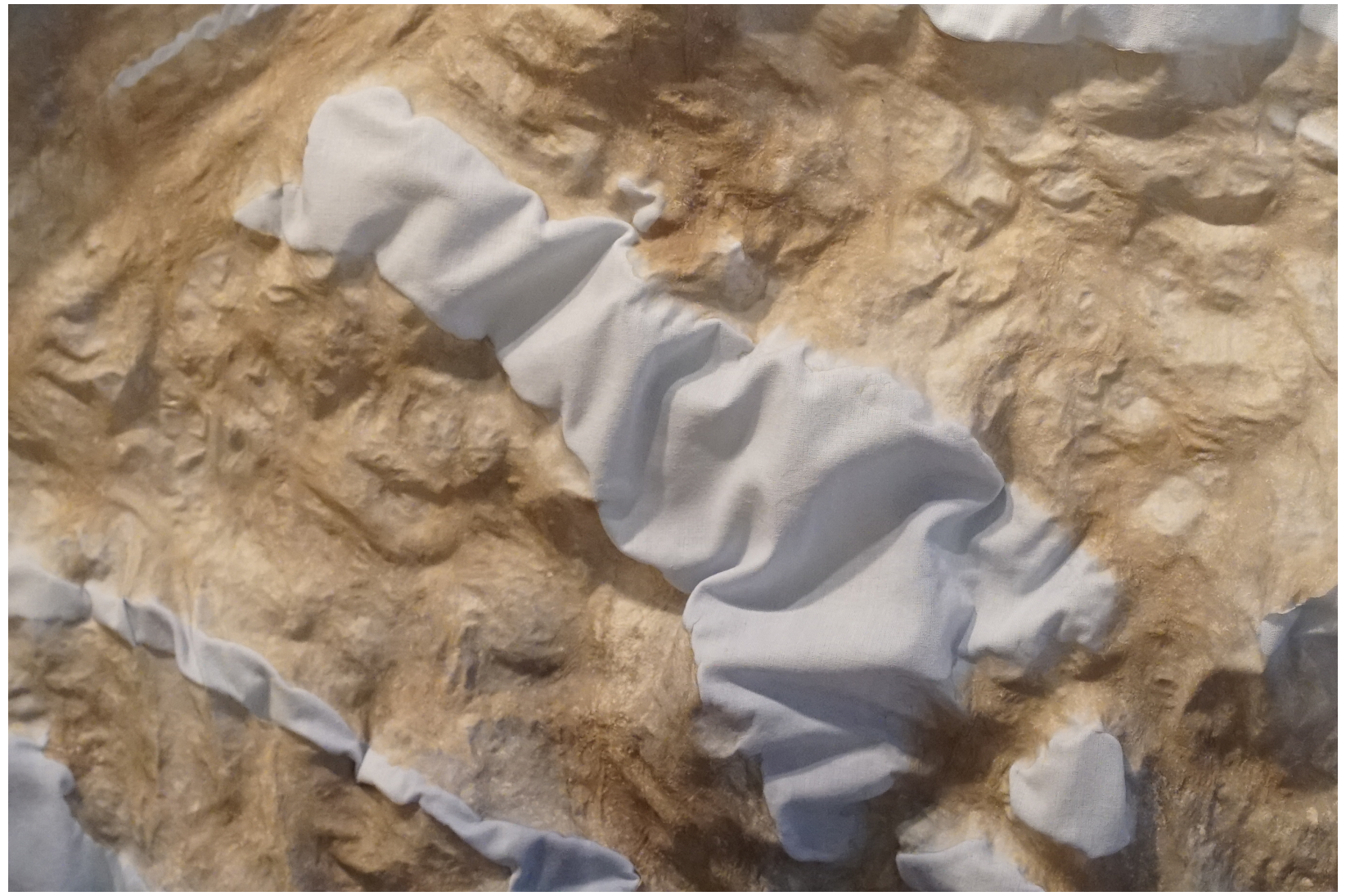

It dramatically impacts the shape of the sculpture... 


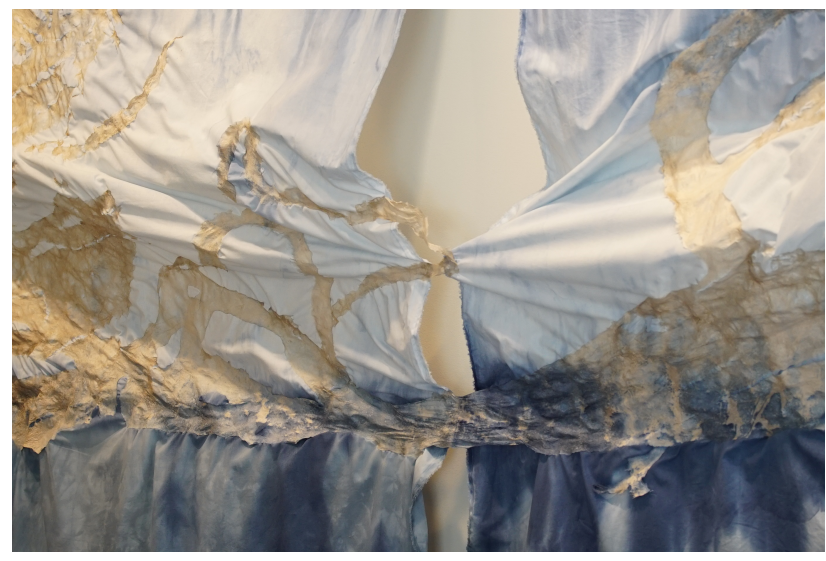

This is a close-up showing detail...

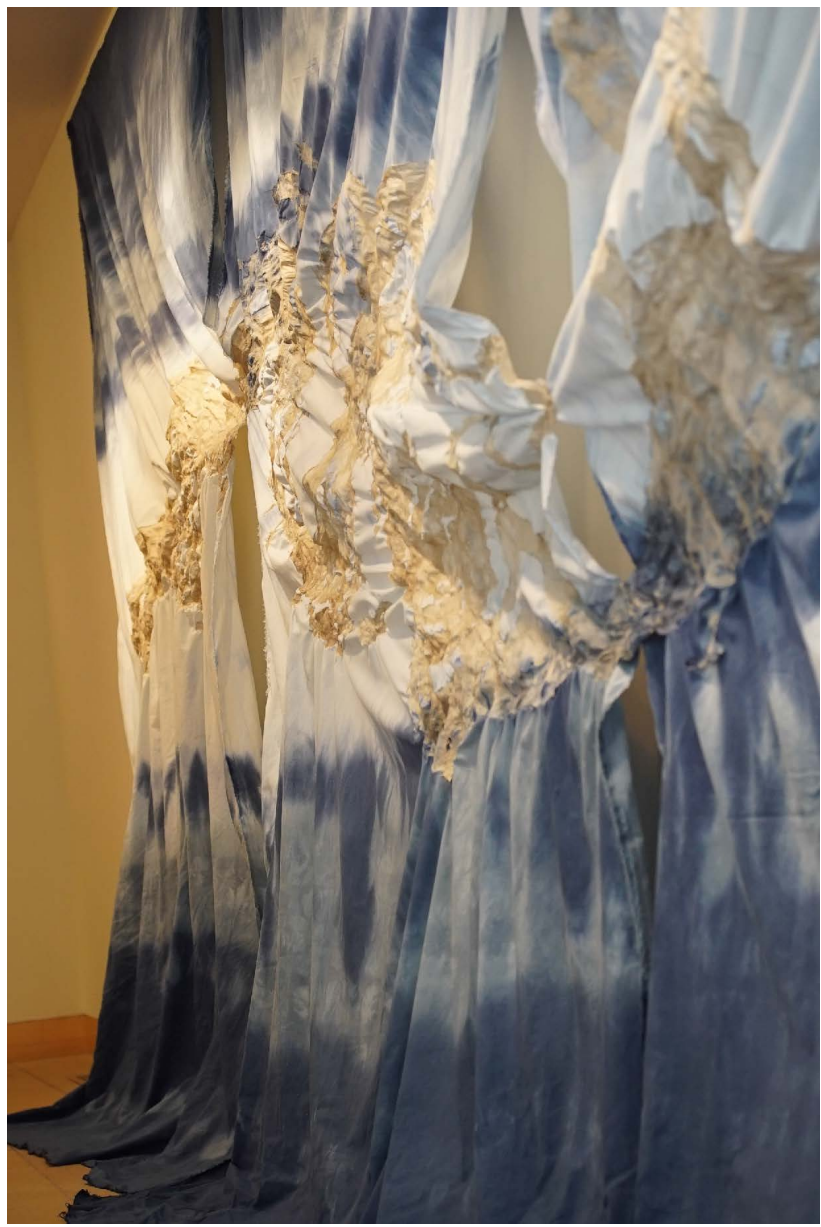

And when completed, this work functioned as a metaphor for the natural movement of water in the landscape: 


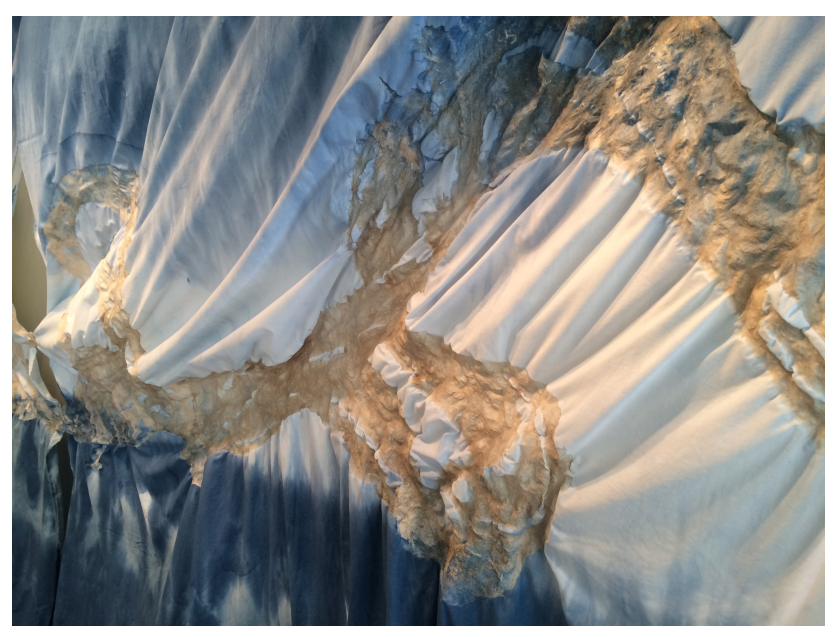

\section{Lee Emma Running.}

Professor of Sculpture and Chair

Department of Studio Art

Grinnell College

runningl@.grinnell.edu

This event is supported by the National Science Foundation, Award \#1929601. Any opinions, findings, and conclusions or recommendations expressed in this material are those of the author(s) and do not necessarily reflect the views of the National Science Foundation. 